\title{
Treatable inherited metabolic disorders causing intellectual disability: 2021 review and digital app
}

Eva M. M. Hoytema van Konijnenburg ${ }^{1 \dagger}$, Saskia B. Wortmann ${ }^{2,3,4 \dagger}$, Marina J. Koelewijn², Laura A. Tseng 1,4, Roderick Houben ${ }^{6}$, Sylvia Stöckler-lpsiroglu ${ }^{5}$, Carlos R. Ferreira ${ }^{7}$ and Clara D. M. van Karnebeek ${ }^{1,2,48^{*}}$ (D)

\begin{abstract}
Background: The Treatable ID App was created in 2012 as digital tool to improve early recognition and intervention for treatable inherited metabolic disorders (IMDs) presenting with global developmental delay and intellectual disability (collectively 'treatable IDs'). Our aim is to update the 2012 review on treatable IDs and App to capture the advances made in the identification of new IMDs along with increased pathophysiological insights catalyzing therapeutic development and implementation.
\end{abstract}

Methods: Two independent reviewers queried PubMed, OMIM and Orphanet databases to reassess all previously included disorders and therapies and to identify all reports on Treatable IDs published between 2012 and 2021. These were included if listed in the International Classification of IMDs (ICIMD) and presenting with ID as a major feature, and if published evidence for a therapeutic intervention improving ID primary and/or secondary outcomes is available. Data on clinical symptoms, diagnostic testing, treatment strategies, effects on outcomes, and evidence levels were extracted and evaluated by the reviewers and external experts. The generated knowledge was translated into a diagnostic algorithm and updated version of the App with novel features.

Results: Our review identified 116 treatable IDs (139 genes), of which 44 newly identified, belonging to 17 ICIMD categories. The most frequent therapeutic interventions were nutritional, pharmacological and vitamin and trace element supplementation. Evidence level varied from 1 to 3 (trials, cohort studies, case-control studies) for 19\% and 4-5 (case-report, expert opinion) for $81 \%$ of treatments. Reported effects included improvement of clinical deterioration in 62\%, neurological manifestations in 47\% and development in 37\%.

Conclusion: The number of treatable IDs identified by our literature review increased by more than one-third in eight years. Although there has been much attention to gene-based and enzyme replacement therapy, the majority of effective treatments are nutritional, which are relatively affordable, widely available and (often) surprisingly effective. We present a diagnostic algorithm (adjustable to local resources and expertise) and the updated App to facilitate a swift and accurate workup, prioritizing treatable IDs. Our digital tool is freely available as Native and Web App (www.treatable-id.org) with several novel features. Our Treatable ID endeavor contributes to the Treatabolome

\footnotetext{
*Correspondence: clara.vankarnebeek@radboudumc.nl

${ }^{\dagger}$ Eva M. M. Hoytema van Konijnenburg and Saskia B. Wortmann have contributed equally to this work

1 Department of Pediatrics, Amsterdam UMC, Amsterdam, The Netherlands

Full list of author information is available at the end of the article
}

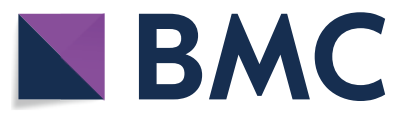

(c) The Author(s) 2021. Open Access This article is licensed under a Creative Commons Attribution 4.0 International License, which permits use, sharing, adaptation, distribution and reproduction in any medium or format, as long as you give appropriate credit to the original author(s) and the source, provide a link to the Creative Commons licence, and indicate if changes were made. The images or other third party material in this article are included in the article's Creative Commons licence, unless indicated otherwise in a credit line to the material. If material is not included in the article's Creative Commons licence and your intended use is not permitted by statutory regulation or exceeds the permitted use, you will need to obtain permission directly from the copyright holder. To view a copy of this licence, visit http://creativecommons.org/licenses/by/4.0/. The Creative Commons Public Domain Dedication waiver (http://creativeco mmons.org/publicdomain/zero/1.0/) applies to the data made available in this article, unless otherwise stated in a credit line to the data. 
and International Rare Diseases Research Consortium goals, enabling clinicians to deliver rapid evidence-based interventions to our rare disease patients.

Keywords: Inborn error of metabolism, Metabolic disorders, Management, Therapy, Epilepsy, Intellectual developmental disorders, Diet, Pharmacological, Nutraceutical, Diagnostic, Outcomes, Evidence

\section{Background}

The past decade has seen revolutionary changes in the diagnosis and discovery of inherited metabolic disorders (IMDs), as well as development of new treatments [1]. Trials with small patient numbers remain challenging, but new methods for trial design, e.g., using natural history data as controls and crossover n-of- 1 designs, have advanced our ability to determine whether treatments are effective or not [2]. What have these advances meant over the past decade for the treatment options of global developmental delay (DD according to the definition in Table 1A) and intellectual disability (ID), which is characterized by limitations starting before the age of 18 years in both intellectual functioning (IQ less than 70) and adaptive behavior. Our systematic literature review changed paradigms for this previously considered untreatable condition affecting $1-3 \%$ of the world's population with substantial comorbidity, high lifetime costs, and emotional burden by identifying 81 treatable IDs in 2012, which increased to 89 in 2014 [3, 4]. With our review, we aimed to increase awareness and avoid the diagnostic and treatment delays so often suffered by rare diseases patients, with $25 \%$ of patients waiting 5 to 30 years for a diagnosis alone [5]. Now once again we address this medical gap and present an updated list of all Treatable IDs, which we define as IMDs which present with global developmental delay (DD) or ID yet are amenable to interventions targeting pathophysiology (e.g., nutraceutical, pharmacological, surgical, etc.) if initiated in a timely fashion.

There are several developments that should be considered to place the current overview of Treatable IDs in perspective. First, the new all-inclusive definition of an IMD, proposed in 2015 by Morava et al. [6] and recently endorsed by the international metabolic community in the International Classification of Inherited Metabolic Disorders (ICIMD): 'Any condition in which the impairment of a biochemical pathway is intrinsic to the pathophysiology of the disease, regardless of whether there are abnormalities in currently available biochemical laboratory tests'(http://www.icimd.org) [7]. The number of IMDs now exceeds 1400 [8]. Second, the practice change our diagnostic algorithm has inspired, with international professional societies now prioritizing IMDs in the diagnostic evaluation of patients with ID in whom the cause is not evident after a thorough clinical exam [9-11] The
Table 1 A and B Definitions and search terms

\section{A. Definitions used in literature review}

Global developmental delay (DD): applied to age $<5$ years; significant delay (= performance two standard deviations or more below the mean on age-appropriate, standardised norm-referenced testing) in two or more developmental domains including gross/fine motor skills, speech/language, cognition, social/personal, activities of daily living [53]

Intellectual disability (ID): applied to age $\geq 5$ years and manifesting before age 18 years, historically referred to as 'mental retardation'; intellectual functioning level (IQ) less than 70 to 75 and significant limitations in two or more adaptive skills $[54,55]$

Inherited Metabolic Disorder (IMD): impairment of specific enzymes or biochemical pathways that is intrinsic to the pathomechanism. The presence of an abnormal metabolite is no longer a prerequisite [6]. This term excludes endocrine disorders such as hypothyroidism

Causal of ID/DD: sufficient evidence in literature from bench and/or clinical research to make a pathophysiological relationship between IMD and ID/DD highly likely

Treatable ID: if a particular therapeutic modality is capable of preventing or improving ID/DD phenotype, or halting/slowing neurocognitive decline (with acceptable adverse effects) in the IMD, i.e., positively influencing the 'outcome measures'

Treatment strategies:

Nutritional therapy, vitamin \& trace element, enzyme replacement therapy, hematopoietic stem cell transplant, solid organ transplantation, pharmacological therapy, gene-based therapy, other (e.g., hemodialysis)

Outcome measure/effect: $A$ = improves psychomotor/cognitive development/IQ, B = improves behavioural/psychiatric disturbance(s), $C=$ prevents acute metabolic decompensation, $\mathrm{D}=$ prevents, halts, or slows clinical deterioration, $\mathrm{E}=$ improves neurological manifestations (incl. neuro-imaging), $\mathrm{F}=$ improves seizure/epilepsy control, $\mathrm{G}=$ improves systemic manifestations

Levels of evidence: Level of evidence: Level $1 \mathrm{a}=$ systematic review

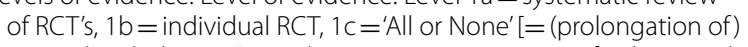
survival with therapy]; Level $2 a=$ systematic review of cohort studies, $2 \mathrm{~b}=$ individual cohort study, $2 \mathrm{c}=$ 'Outcomes Research' [focused on end results of therapy for chronic conditions, including functioning and quality of life]; Level $3=$ systematic review of case-control studies; Level $4=$ individual case-control study or case-series/report; Level $5=$ expert opinion without critical appraisal; based on physiology, bench research or first principles. If only one patient was reported, we assigned level ' $4-5$ ' as a way to nuance the treatment effects

B. Terms used for search strategy in PubMed [56]

Developmental delay/intellectual disability: mental retardation, learning disorder(s), developmental disability/ disabilities, learning disability/ disabilities, intellectual disability/disabilities, developmental delay, intelligence/classification, mentally disabled (persons), childhood/juvenile Alzheimer's, childhood/juvenile dementia, neurodegenerative disease Inherited Metabolic Disorder: metabolic disease(s), inborn error(s) of metabolism, metabolic disorder(s), metabolic condition(s), inherited metabolic disease(s), inherited metabolic disorder(s), biochemical disease(s)

Treatment: treatment, management, therapy, cure, trial, (dietary) supplement, (dietary) restriction, diet, substrate inhibition, small molecule substrate reduction, enzyme replacement, vitamin(s), co-factor(s), bone marrow transplant, hematopoietic stem cell transplant, umbilical cord blood transplant(-ation), gene therapy 
digital tool 'Treatable ID' has certainly given this innovation a boost [12] as its digital accessibility proved useful both for educational as well as practical purposes (e.g., Continuum Child Neurology [13]), especially in remote areas where metabolic expertise might not be available onsite. The Treatable ID App was created in 2012, and is freely accessible as a Web App via http://www.treatableid.org and since 2016 as a Native App via the App Store/ Google Play. The App is designed for a target audience of various specialists evaluating children presenting with ID, both clinicians and laboratory scientists from student to expert level [12]. The Treatable ID App has a steady audience. Over the past 8 years there have been over 75,000 different users for the web App and over 10,000 downloads of the native App. The Treatable ID App is also part of the Treatable Intellectual Disability Endeavor (TIDE) diagnostic protocol [14]. In the second tier of the TIDE algorithm, the Treatable ID App is incorporated to optimize selection of targeted metabolic workup [14]. Also, numerous clinical and commercial labs have requested access to the Treatable ID gene lists for their quick turnaround phenotype-driven (virtual) gene panels. Third, as shown in a retrospective study by Sayson et al., using the Treatable ID algorithm can reduce costs and diagnostic delay for treatable IMDs underlying ID [15]. The same was shown in a prospective way, in our TIDE study which implemented the Treatable ID algorithm in 498 unexplained ID patients referred to a tertiary care centre (biochemical and clinical genetics as well as neurology departments) as add-on to clinical practice parameters at the time (2015). Indeed, this manuscript currently under review illustrates the presence of IMDs $(6 \%)$ in this group of patients, even those without a classical multiorgan or degenerative phenotype (van Karnebeek et al. submitted) [16]. The fourth development is the remarkably large number of clinical trials with great promise, even pioneering gene-based therapy targeting the central nervous system, few of which however have made it to the real-world of reimbursed clinical care, and as such are not included here. Finally, despite the advances, the inequality in access to exome sequencing (ES) and other -omics technologies remains. Indeed, access determines the diagnostic approach; while for some countries and regions, metabolic testing is still the first tier, for others the exome-first approach has become standard of care [17]. Thus, algorithms must be tailored to local possibilities and expertise. Speed and accuracy are warranted as 'time is brain', i.e., early identification and intervention before irreversible damage is done [18]. Increasingly, therapy is center stage; even in the interpretation of genomic variants, response to therapy has been endorsed as a valuable criterion to determine pathogenicity [19]. The ultimate goal of creating a Treatabolome database comprising rare disease treatments at gene and variant levels was recently outlined [20]. Here, we contribute to this goal by presenting an updated state-of the-art overview of all treatable IDs along with a new version of the digital App freely accessible to professionals as well as patients, and suggest an updated diagnostic algorithm.

\section{Material and methods}

Our main goals were: (1) to identify all IMDs presenting with DD and/or ID (collectively termed ID in this paper) as a major feature, which are amenable to treatment targeting pathophysiology, supported by evidence in the literature reported up to January 2021, and (2) to translate this information into an updated version of the Treatable ID digital App, as well as (3) a diagnostic algorithm to facilitate early detection of treatable IMD in patients presenting with unexplained ID.

\section{Literature review}

For our literature review, we used a critical rather than a formal systematic literature review approach to answer the above stated question. We followed the Treatabolome approach as much as possible [20]. The systematic literature review in 2012 and its update in 2014 were used as a basis. Three independent reviewers (EH, CvK, SW) searched and critically appraised the literature, characterized the clinical and diagnostic recognition patterns as well as treatment modalities pertinent to the identified IMDs, and assessed the level of available evidence and effect of the various treatments on clinical outcome measures. The reviewers engaged in regular consensus meetings, and final decisions on any disagreements were reached by a majority vote of the reviewers plus an external expert (CRF).

\section{Identification of treatable IMDs causing ID Literature search}

Definitions of terms relevant for the search strategy and keywords for terms DD, ID, IMD, and treatment are shown in Table 1A and B. We searched PubMed, restricted to English language and publication in peerreviewed journals (http://www.ncbi.nlm.nih.gov/pubmed; 1960-January 2021) in a two-step approach. First, the 89 IMDs included in the 2012 and 2014 database were reassessed under consideration of the additional literature published; second, new treatable IDs were identified and reviewed. Additionally, the reference lists of identified articles, Orphanet [21] and Online Mendelian Inheritance in Man (OMIM) [22] were queried with the same search terms, and experts in the field were approached to identify new treatable IDs. To ensure comprehensiveness of treatment modalities, we identified all relevant references reporting outcome/effect for each of the selected 
treatments and IMDs. We searched bibliographies of included articles as well as PubMed (1960-January 2021) combining as keywords all known names for each IMD (including gene and enzyme) with the relevant therapeutic modalities (Table 1B).

\section{Outcomes and levels of evidence}

The ideal outcome of therapy for a treatable ID is the improvement of IQ and related developmental scores. As improvement of co-morbid features such as epilepsy, neurologic, behavioral or psychiatric problems is often a prerequisite for improved cognitive outcomes, these were included as 'secondary outcomes'. Levels of evidence were defined and applied according to Table 1A.

\section{Effect(s) of treatments on outcome measures}

Effect(s) of treatment outcomes were defined as shown in Table 1A. We included treatments if they had a direct effect on ID (improvement or stabilization), or if there was a reasonable expectation that ID would be improved by significant improvement of other symptoms-such as seizures or severe movement disorders-thus making development possible. Supportive treatments and treatments with improvement only of systemic symptoms that were not reasonably related to ID were not included. If a treatment was not effective for all reported patients, we defined that at least a third of the patients needed to show improvement to ensure inclusion of potential beneficial treatments. All decisions on inclusion and exclusion of IMDs and treatments were mutually agreed upon during a final consensus meeting. In the previous review, a classification about standard of care versus individual basis was assigned to each treatment; given the growing attention to personalized medicine in IMD, we do not feel this distinction appropriate for our current review.

\section{Inclusion/exclusion criteria}

We included IMDs where ID was a major clinical feature (present in more than $50 \%$ of reported patients) and for which evidence supported amenability to the defined treatments with a positive effect on outcomes in at least one-third of patients.

\section{Data extraction}

For all IMDs meeting the criteria of a Treatable ID, the following information was captured:

Name of disease; gene and inheritance pattern; name of biochemical deficiency; group of disorder; screening and specific tests; neurological and non-neurological symptoms (only characteristic, specific and consistent symptoms were noted, see http://www.treatable-ID.org); treatment strategies (see Table 1A for categorization); specific therapies; level of evidence for each treatment and treatment effect (see Table 1A). Names and groups of disorders were based on the most recent ICIMD [7]. Disorders caused by pathogenic variants in multiple genes were reported as separate entries if there were meaningful differences in phenotype or treatment. For practical and user-friendliness purposes, if there were no meaningful differences, genes were grouped or 'lumped' and considered as one IMD.

\section{Compliance to the FAIR guidelines for scientific data management and stewardship}

We adhered as much as possible to the FAIR-compliant (findable, accessible, interoperable, reusable) template that will ultimately enable the building of a 'Treatabolome' database [20,23]. We complied with the recommendations for a broad and inclusive literature search and the main elements of data extraction and data synthesis. The main deviation from the FAIR-compliant template in our review is that, due to the multitude of included IMDs, we did not perform a formal systematic review for each IMD. Furthermore, there are a few specific deviations from the template: we used OMIM gene/locus instead of phenotype OMIM numbers as we considered this approach more precise for the current review, and we did not specify all (contra)indications and marketing authorizations for each treatment due to of the multitude of included IMDs; this was outside the scope of this review.

\section{Diagnostic tests and algorithm}

We used our literature review results to update our diagnosed algorithm proposed in 2014. During the past years, ES has become accepted as first line tier testing in many countries around the world. However, metabolic screening is still applied given the specificity and sensitivity of tests, the short turnaround times and relative affordability and availability [24]. Metabolic profiles can also serve as functional readout, and "deep metabolic phenotyping" can help in the interpretation of genetic data. Therefore, we included both strategies in our algorithm to facilitate a practical guide for biochemical and genetic/ genomic diagnosis. We first assessed which tests are necessary to identify each of the conditions. Accordingly, we grouped the IMDs into those diagnosed via 'metabolic screening tests' (1st Tier) versus IMDs diagnosed via 'single test per single disease' (2nd Tier) approach. First tier screening tests were defined as tests in blood and urine which are readily available in biochemical laboratories in most developed countries. Metabolic tests in the 2nd tier group evaluate Treatable IDs for which biochemical markers are difficult to interpret, and/or conventional diagnostic approach requires an invasive procedure or poorly accessible test (i.e., only performed in few centres 
worldwide). Furthermore, we analyzed which IMDs have no (reliable) biomarker profile and require primary molecular or (targeted) ES analysis. This approach with different strategies and tiers was then translated into a step-wise algorithm.

\section{Treatable ID App design and development}

The Treatable ID App was created in 2012 and later updated based on the 2012 and 2014 literature reviews [3, 4]. In 2021, the Treatable ID App has been updated and improved extensively both in content and design. The content is updated based on our 2021 literature search with updated and increased links to useful resources for each IMD. The design has been adapted to 2021 standards with a quick and solid interface. Both the Web App and the Native App use the same database which is an improvement over the previous version. As a result, new information can be added easily and this will ensure the content is always up to date. The database is built in Oracle.

The Web App can be used in all major browsers and the Native app can be downloaded from the App Store and Google Play. The creation of the Treatable ID App is supported and funded by the 'Metakids Foundation' in The Netherlands [25].

\section{Results}

\section{Literature review}

Treatable IDs

Our first systematic review identified 81 treatable IDs [3] and was updated with another 8 disorders in 2014 [4]. From these 89 disorders, our current literature search led to exclusion of 20 treatable IDs, because of insufficient evidence for effect of treatment on established outcome measures $(n=10)$, ID no longer considered a major clinical feature $(\mathrm{n}=8)$, metabolic defect not causative of ID $(\mathrm{n}=1)$ and duplicate disorder $(\mathrm{n}=1)$. The disorders are listed in Additional File 1: Table 1.

Of the 69 remaining treatable IDs we grouped the following IMDs according to the method described: (1) Glycine encephalopathy due to aminomethyltransferase $(A M T)$ or glycine decarboxylase (GLDC) deficiency; (2) Electron transfer flavoprotein subunit alpha $(E T F A) /$ subunit beta $(E T F B) /$ dehydrogenase deficiency $(E T F D H) ; 3)$ Branched-chain ketoacid dehydrogenase $\mathrm{E} 1$ alpha $(B C K$ $D H A) /$ beta $(B C K D H B) / E 2(D B T)$ deficiency; (4) Propionic acidemia due to propionyl-CoA carboxylase subunit alpha $(P C C A)$ /beta $(P C C B)$ deficiency; (5) Niemann-Pick disease type $\mathrm{C} 1$ (NPC1)/C2 (NPC2); (6) Pyruvate dehydrogenase E1 alpha (PDHA1)/beta (PDHB)/E2 (DLAT)/ E3 $(D L D) /$ E3BP $(P D H X)$ deficiency; (7) ATP-sensitive potassium channel regulatory/pore-forming subunit superactivity $(A B C C 8 / K C N J 11)$; (8) Mitochondrial myopathy, encephalopathy, lactic acidosis and strokelike episodes (MTTL1/MTTQ/MTTH/MTTK/MTTC/ MTTS1/MTND1/MTND5/MTND6/MTTS2).

We further 'split' two previously grouped ('lumped') disorders into five separate disease entities: 1) Coenzyme Q5 methyltransferase deficiency, 2) Coenzyme Q8A (ADCK3) deficiency, 3) Methylmalonic aciduria and homocystinuria, cblD type, 4) Homocystinuria, cblDv1 type, 5) Methylmalonic aciduria, cblDv2 type. This led to a final list of 72 treatable IDs that were already included in the 2014 database. Our literature search for "new" treatable IDs identified 44 disorders, combining to a total number of 116 treatable IDs included in this 2021 update and shown in Table 2 (new disorders are marked with an *).

\section{Classification}

Included treatable IDs belonged to the following 17 ICIMD categories: vitamin and cofactor metabolism 29 (25\%), amino acid metabolism 28 (24\%), complex molecule degradation 10 (9\%), neurotransmitters 9 (8\%), nucleobase, nucleotide and nucleic acid metabolism 7 (6\%), disorders of glycosylation 6 (5\%), energy substrate metabolism $5(4 \%)$, trace elements and metals $5(4 \%)$, fatty acid, carnitine, and ketone body metabolism 5 (4\%), lipid metabolism 3 (3\%), mitochondrial cofactor biosynthesis $2(2 \%)$, other disorders of mitochondrial function $2(2 \%)$, carbohydrate metabolism $1(1 \%)$, peptide and amine metabolism 1 (1\%), endocrine metabolic disorders $1(1 \%)$, mtDNA-related disorders $1(1 \%)$, and nuclearencoded disorders of oxidative phosphorylation 1 (1\%).

\section{Types of treatment and levels of evidence}

The different types of treatment as defined in Table $1 \mathrm{~A}$ are shown per disorder in Table 3. Nutritional therapy was the most frequently used treatment strategy (32\%), followed by pharmacological therapy $22 \%$, vitamin and trace element substitution $22 \%$, solid organ transplantation $8 \%$, hematopoietic stem cell transplant $4 \%$, enzyme replacement therapy $3 \%$, gene-based therapy $2 \%$ and other therapy $7 \%$ (multiple treatments per disease entity were possible).

The level of evidence for each treatment as defined in Table 1A is shown in Table 3. Most often, case series or case reports with an evidence level of $4(60 \%), 4-5$ $(12 \%)$ and 5 (8\%) were reported; higher evidence levels accounted for a minority (level 1 for $4 \%$, level 2 for $14 \%$, level 3 for $0.5 \%$ ) (Table 3).

\section{Effect(s) of treatments on outcome measures}

Treatment prevented, halted, or slowed clinical deterioration in $62 \%$, improved neurological manifestations 


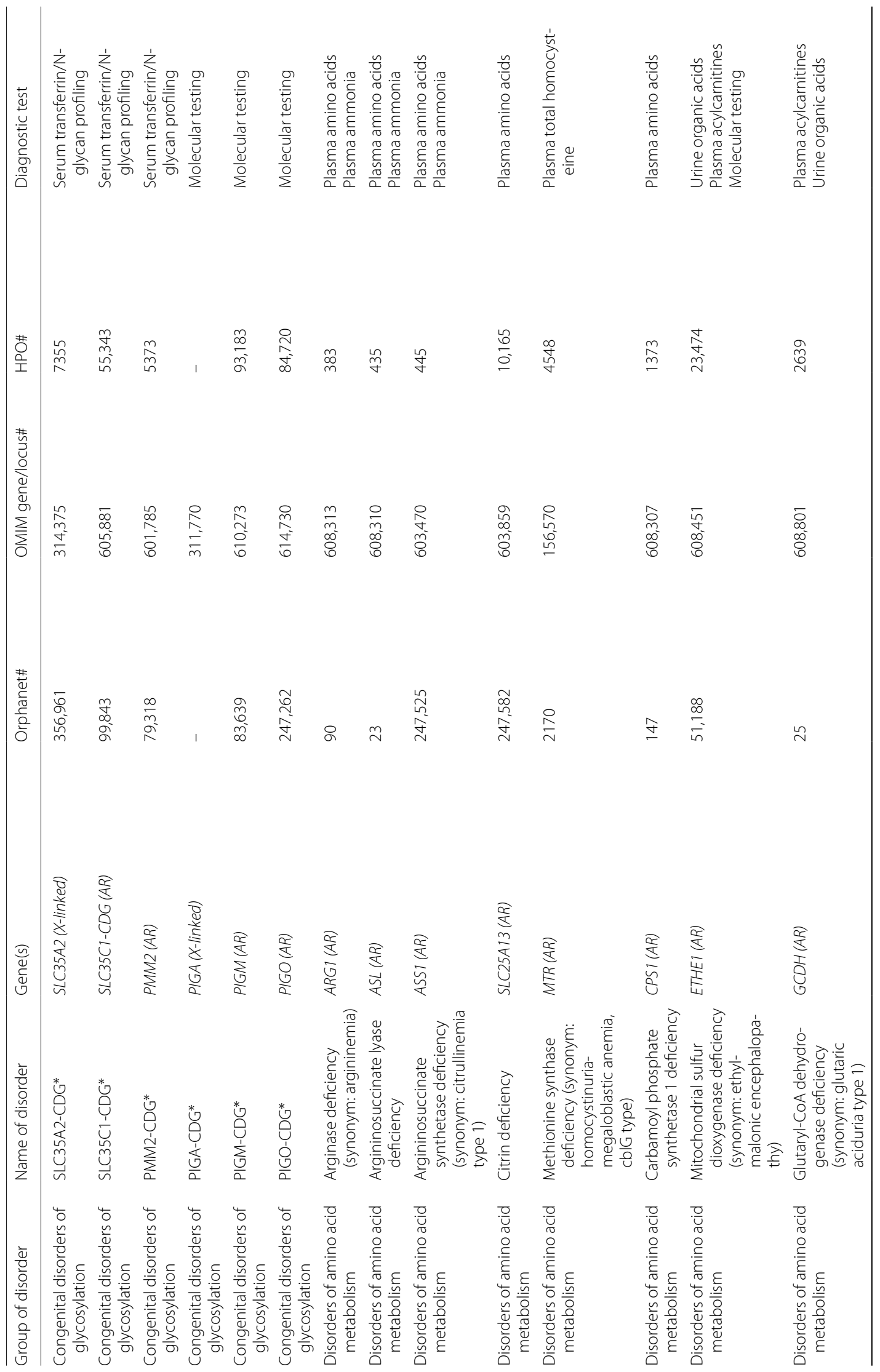




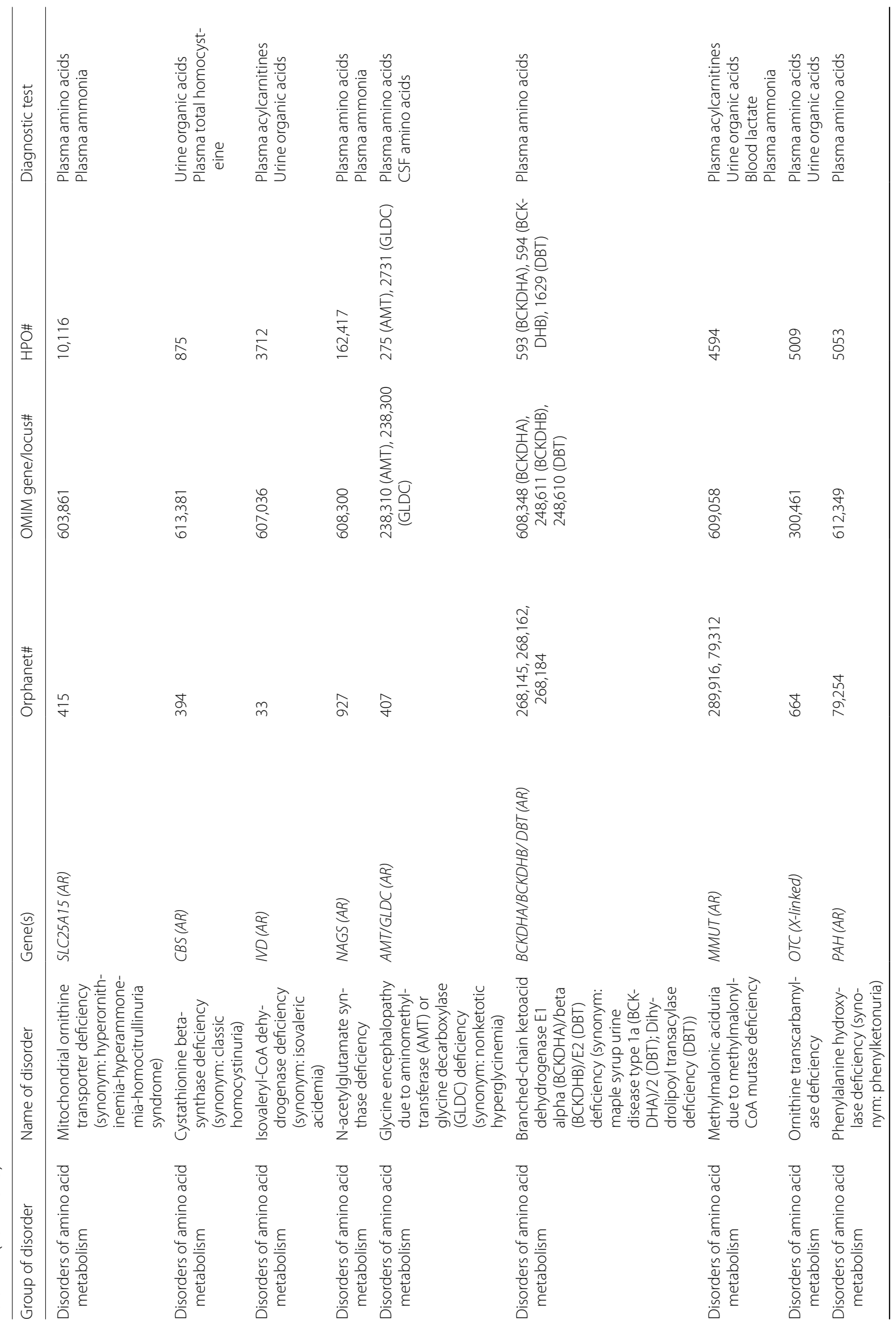




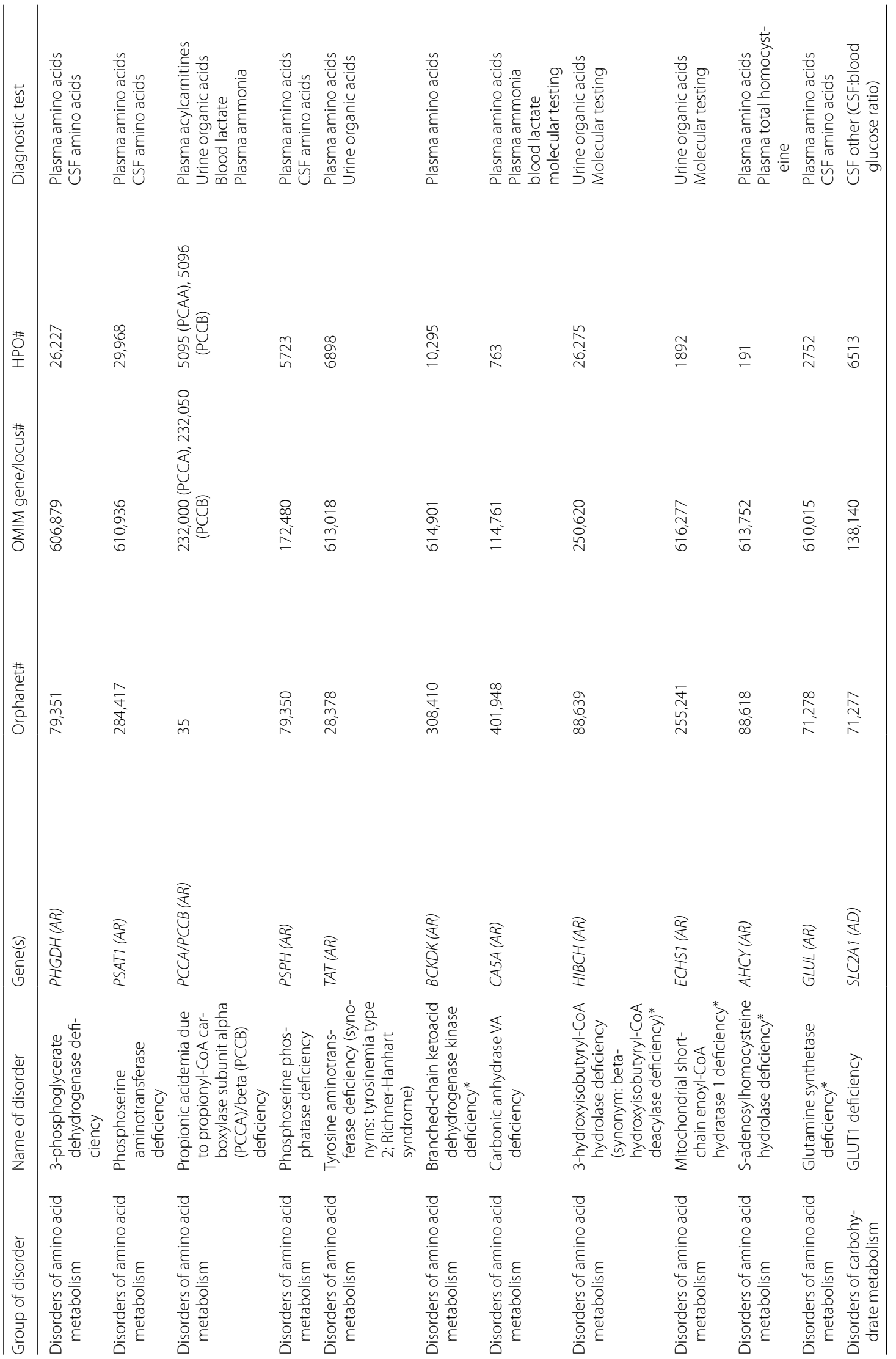




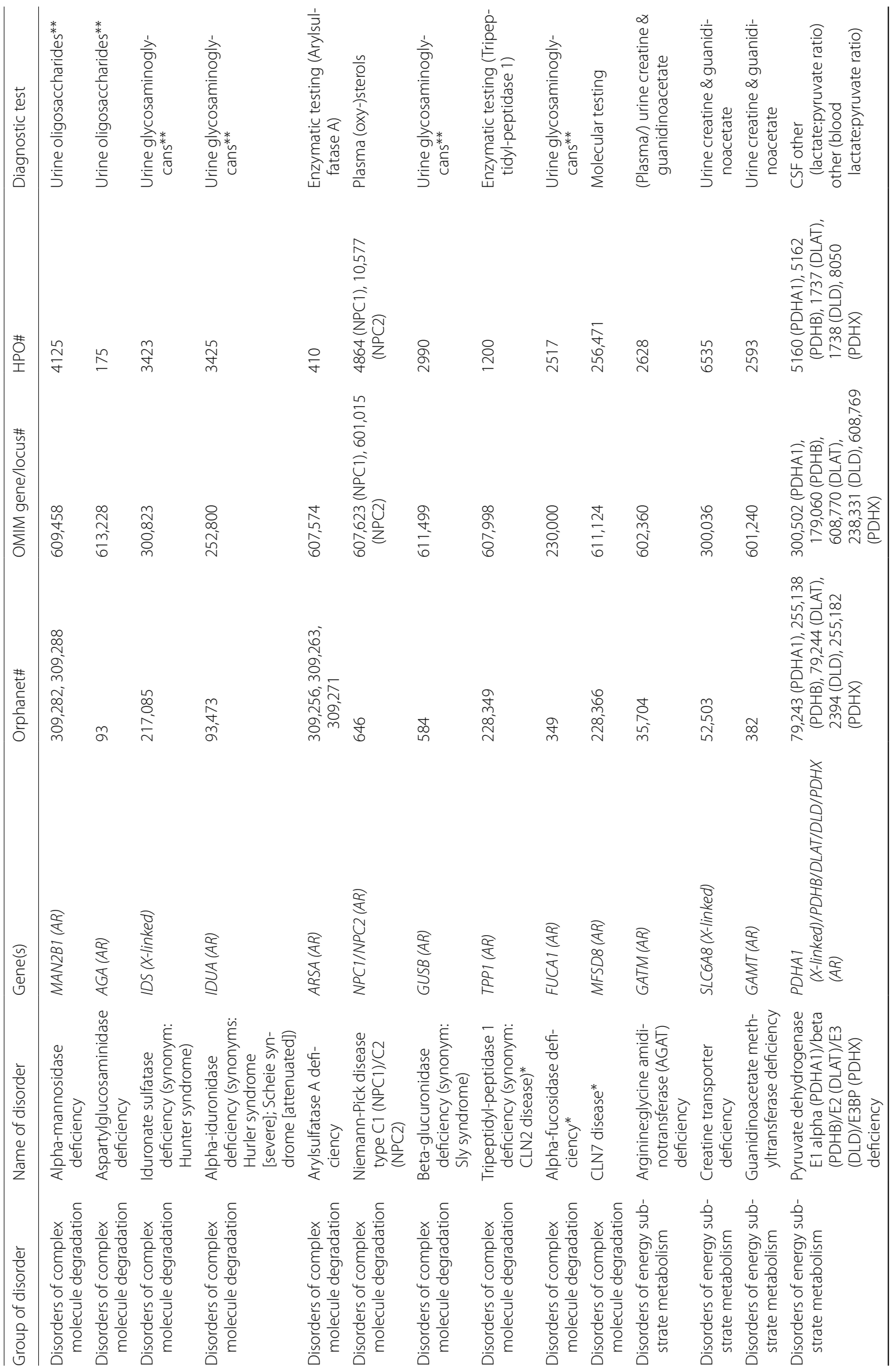




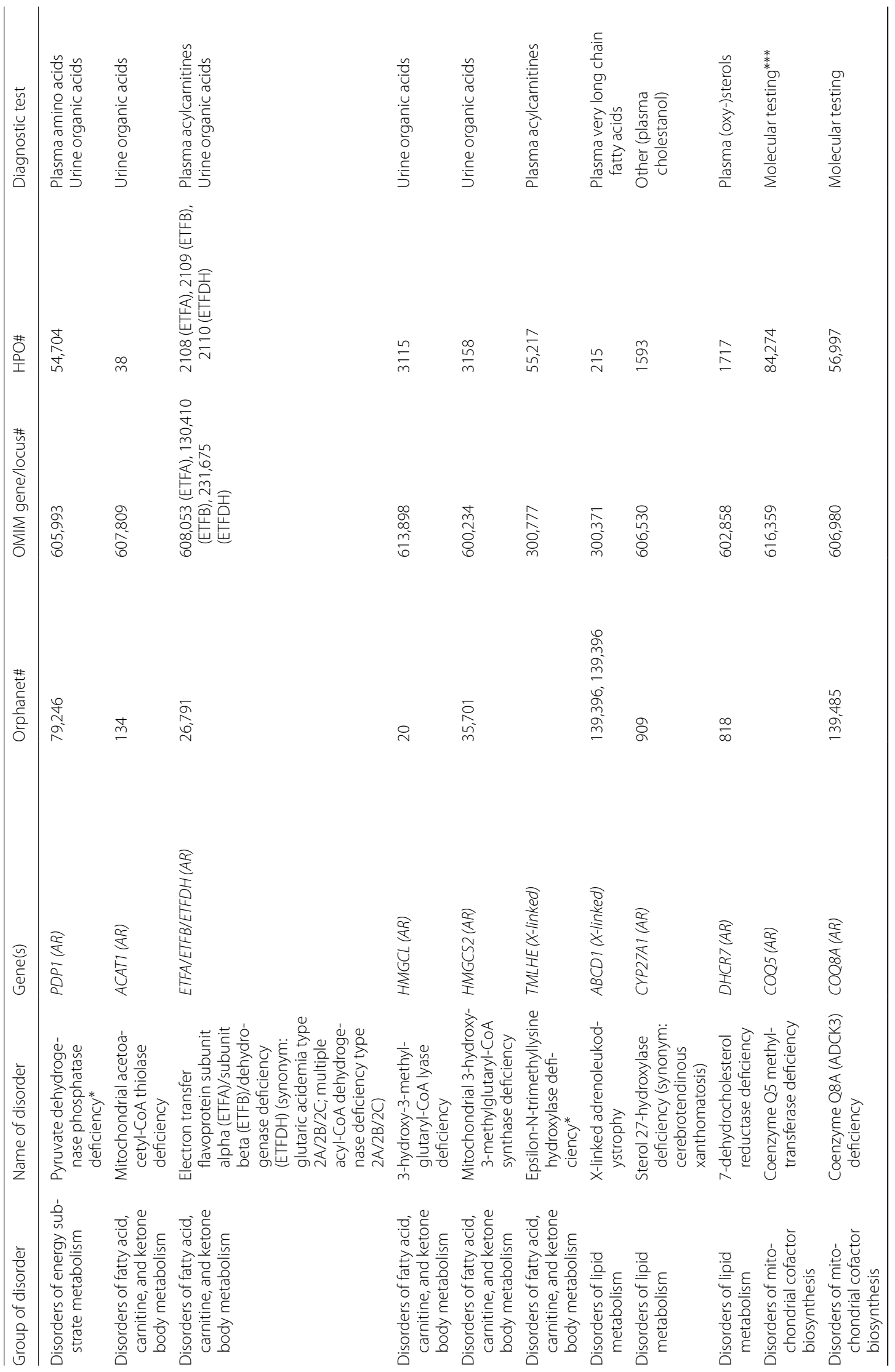




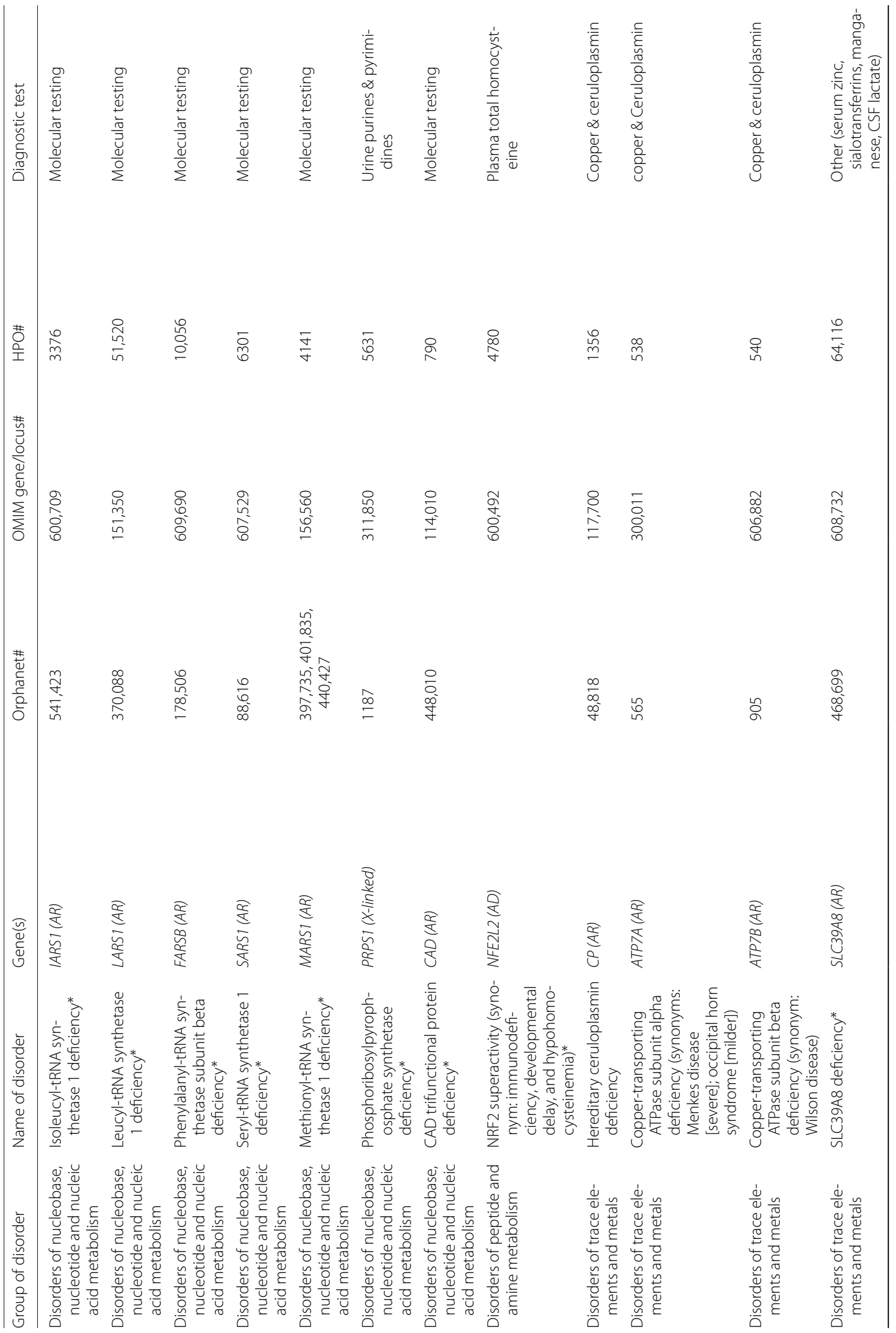




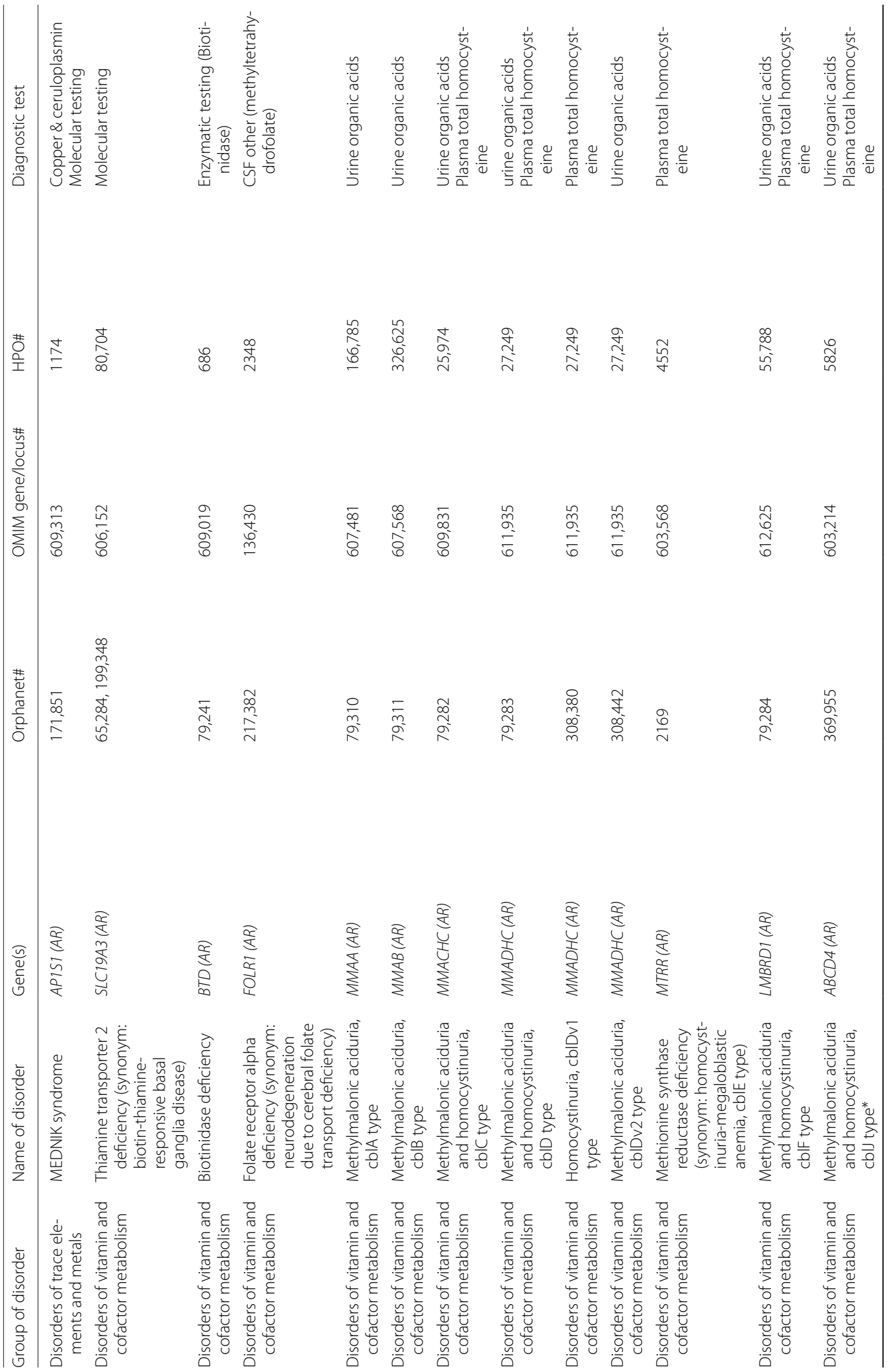




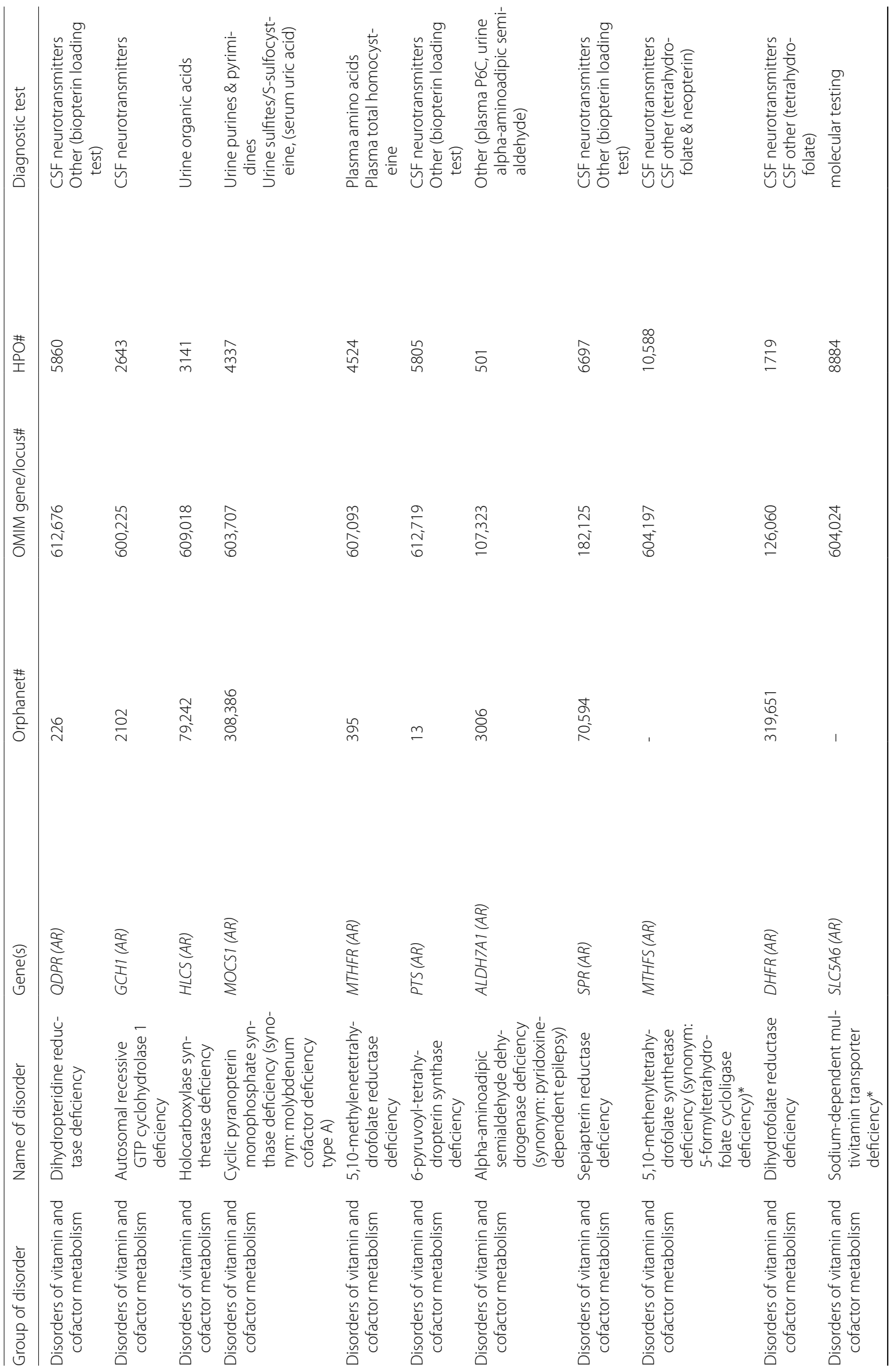




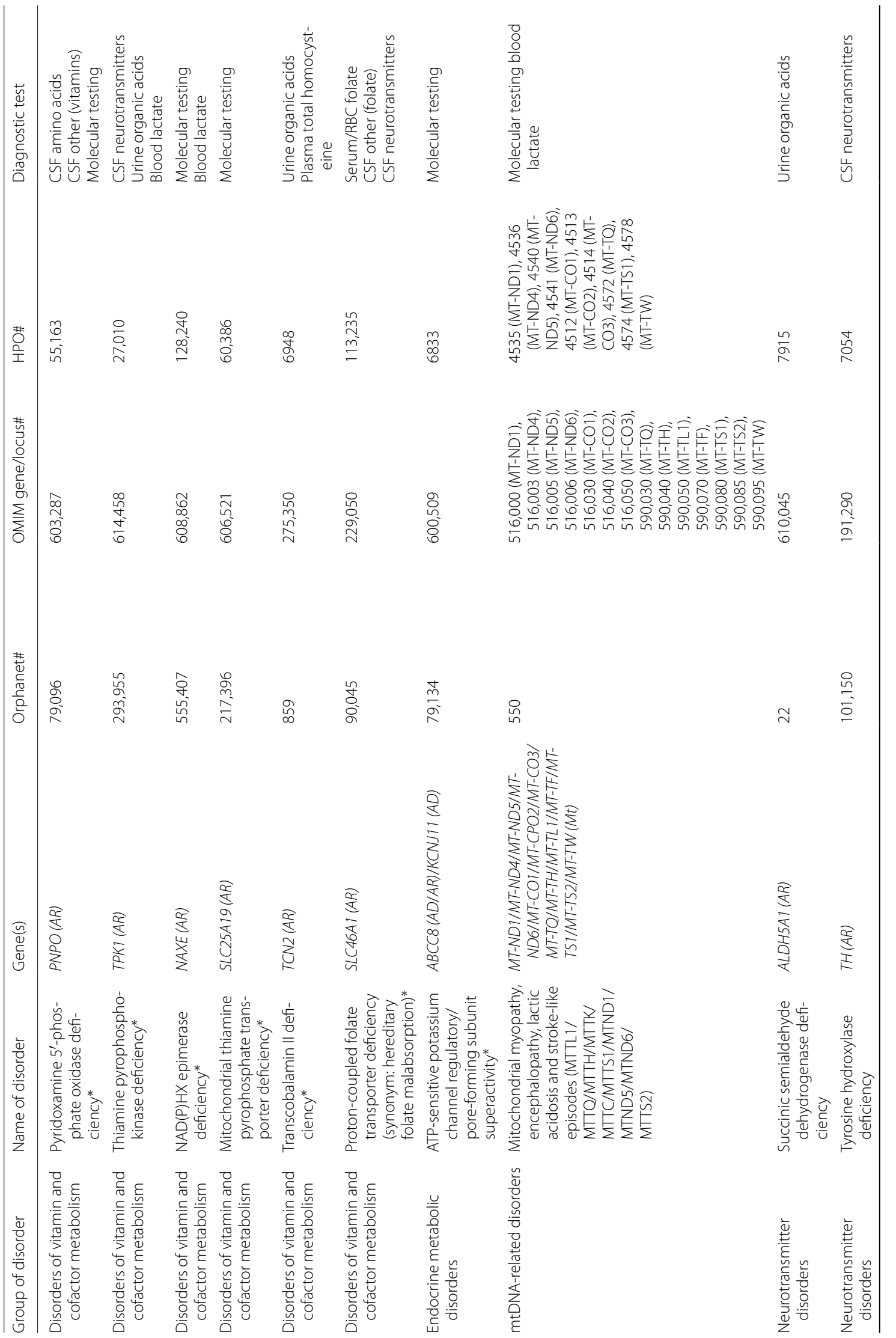




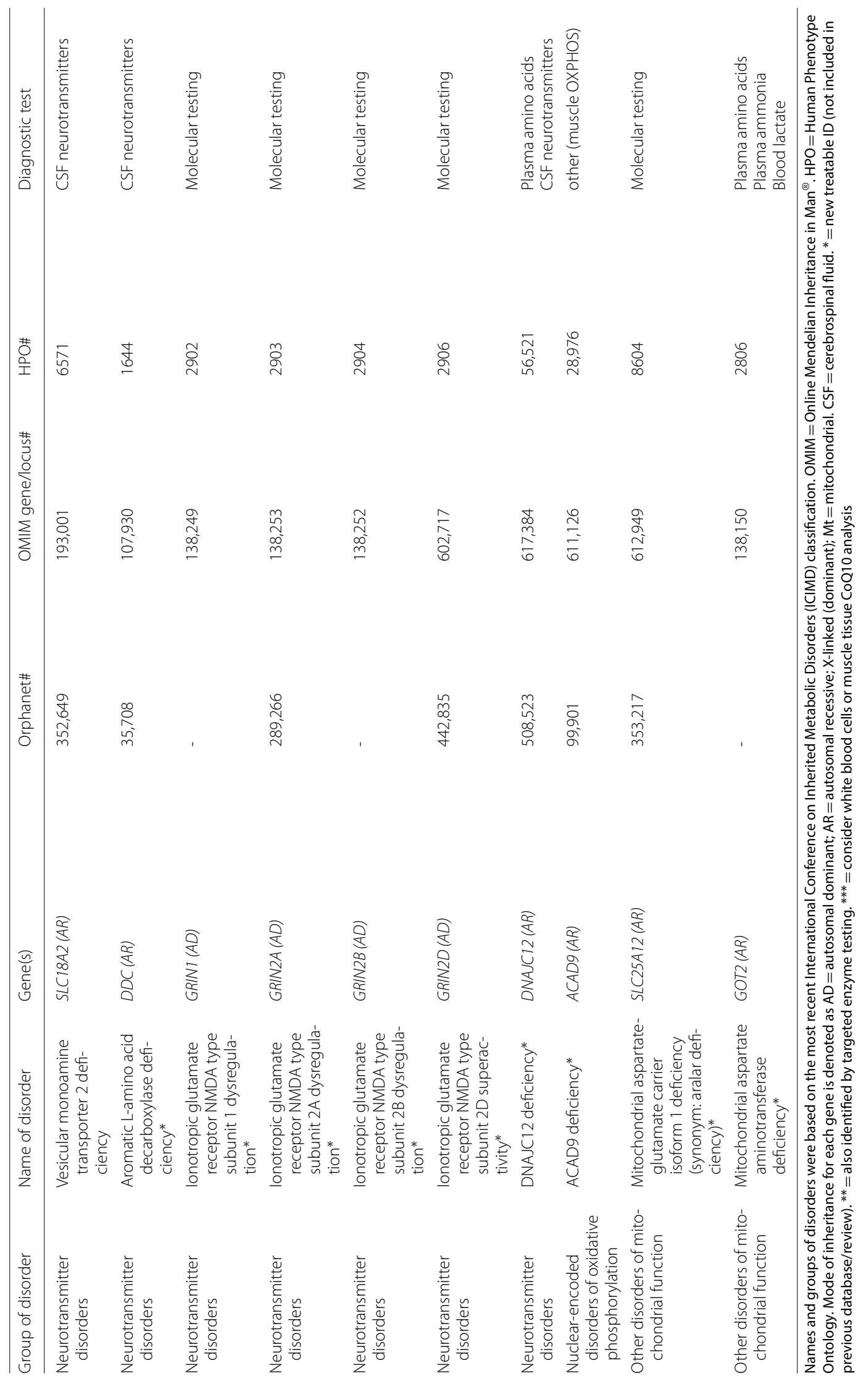


(incl. neuro-imaging) in $47 \%$, systemic manifestations in $44 \%$ and psychomotor/cognitive development/IQ in 37\%; it prevented acute metabolic decompensation in 30\%, improved seizure/epilepsy control in $22 \%$ and improved behavioural/psychiatric disturbance(s) in $21 \%$.

\section{Diagnostic algorithm}

The diagnostic algorithm in Fig. 1 is proposed for the evaluation of a patient of any age presenting with DD or ID in whom the cause is not apparent. It is based on the following results: $1^{\text {st }}$ Tier or 'basic' metabolic screening (in blood: lactate, plasma ammonia, serum transferrin/Nglycan profiling, serum/red blood cell folate, serum copper and ceruloplasmin, plasma amino acids, plasma total homocysteine, plasma (or dried bloodspot) acylcarnitines, very long chain fatty acids; in urine: organic acids, creatine, guanidinoacetate, glycosaminoglycans and oligosaccharides) is available at most if not all diagnostic metabolic laboratories and can identify 69 (59\%) of the 116 treatable IDs. Of course, further biochemical and genetic confirmation is warranted, but for the sake of prompt initiation of treatment, these first-tier results yield sufficient diagnostic information.

Importantly, for 23 of 116 IMDs (20\%) no specific biomarker is currently available and thus molecular testing (targeted or via exome) is required (Fig. 1).

Lumbar puncture for cerebrospinal fluid (CSF) neurotransmitter and amino-acid analysis is indicated in patients with neonatal or infantile seizures of unknown aetiology, dystonia or other movement disorders, progressive intellectual neurological deterioration (85 IMDs, $41 \%$ amenable to treatment [26]), severe psychiatric or behavioral phenotypes, and/or clinical findings suggestive of dopamine deficiency (hypersalivation, temperature dysregulation, oculogyric crises, or hypokinesia). An abnormal profile has important diagnostic as well as therapeutic implications, such as neurotransmitter supplementation, e.g., in GTCPH deficiency, or even in additional non-classic IMDs, e.g., in a PAK3 deficiency patient with severe automutilation and low CSF homovanillic acid (HVA) [27].

\section{Treatable ID App}

First, based on our 2021 literature search, the content has been updated in the Treatable ID App, including updated summaries, symptoms, diagnostic tests, treatments with levels of evidence and effects for each IMD. A disorder page has been designed of each IMD with links to Orphanet, OMIM, Human Phenotype Ontology (HPO), GeneReviews, GeneCards, IMDbase, Vademecum Metabolicum and WikiPathways. Second, based on user feedback, the design has been updated with a quick and solid interface. It is possible to search based on signs and symptoms for IMDs, the appropriate diagnostic tests and gene lists and panel designs, available treatments and evidence. Figure 2 illustrates the Treatable ID App features on mobile devices. The App is available via the App Store, Google Play and online (http://www.treatable-id. org) freely downloadable for all interested users including but not limited to general practitioners, medical and biochemical geneticists, neurologists, developmental and pediatricians, internists, metabolic diseases specialists, as well as laboratory specialists and patients and families.

\section{Discussion}

\section{Targeted therapies for treatable IDs: strengthening} the Treatabolome

Our systematic review from 2012 was the first to prioritize the treatability in the diagnostic evaluation of patients with DD and ID in whom the cause was not evident after a thorough clinical exam. As increasing numbers of patients are diagnosed through exome and genome sequencing in clinical practice or within research projects, it becomes ever more crucial to enable flagging of potentially treatable cases at a gene or variant level. However, this knowledge was (and still is) largely available only in 'human-readable' scientific publications or in expert practice, and our website and app were the first to capture this knowledge in a computer-accessible form that would allow automatic recognition and flagging in analysis and decision-support systems. The implementation of these web resources in national guidelines as well as treatment programs has successfully changed the clinical practice and inspired several reviews on other genetic diseases (e.g., neuromuscular disease [28], epilepsy [17] or movement disorders [29]). The final goal is a 'treatabolome' database accessible for all health care providers as well as patients.

\section{Diagnostics advances}

The field of IMDs is a moving target with 44 newlydefined IMDs included in our recent update, and still the IMDs are the largest group of monogenic conditions underlying ID amenable to treatment. The wide implementation of NGS techniques has led to the identification of new IMDs and the better understanding of the underlying pathophysiology has led to a substantial change in the definition of IMDs ('Any condition in which the impairment of a biochemical pathway is intrinsic to the pathophysiology of the disease, regardless of whether there are abnormalities in currently available biochemical laboratory tests'). These changes led to an increasing number of individuals being diagnosed with IMDs for which no metabolic marker is available (e.g., CAD 


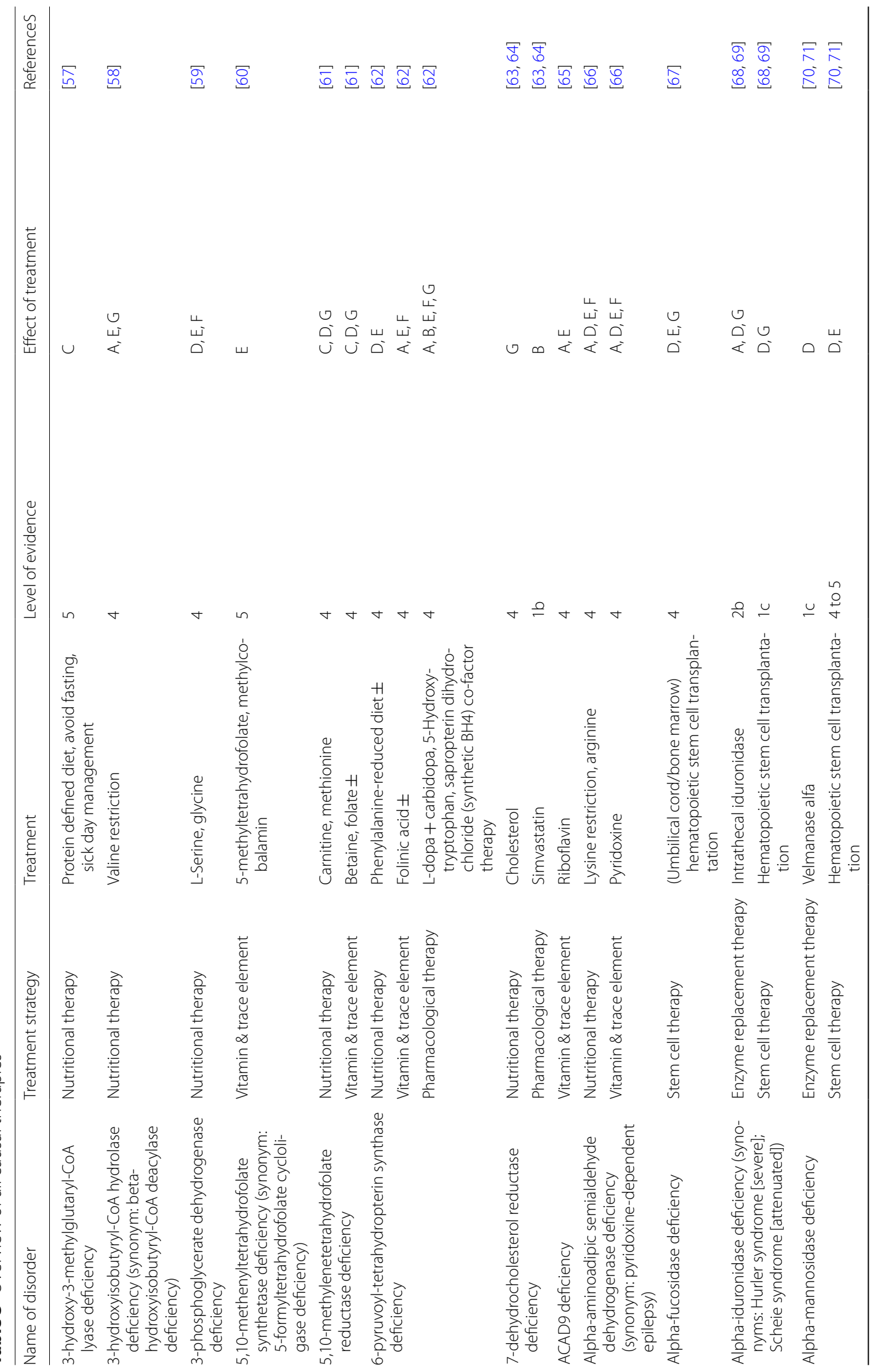




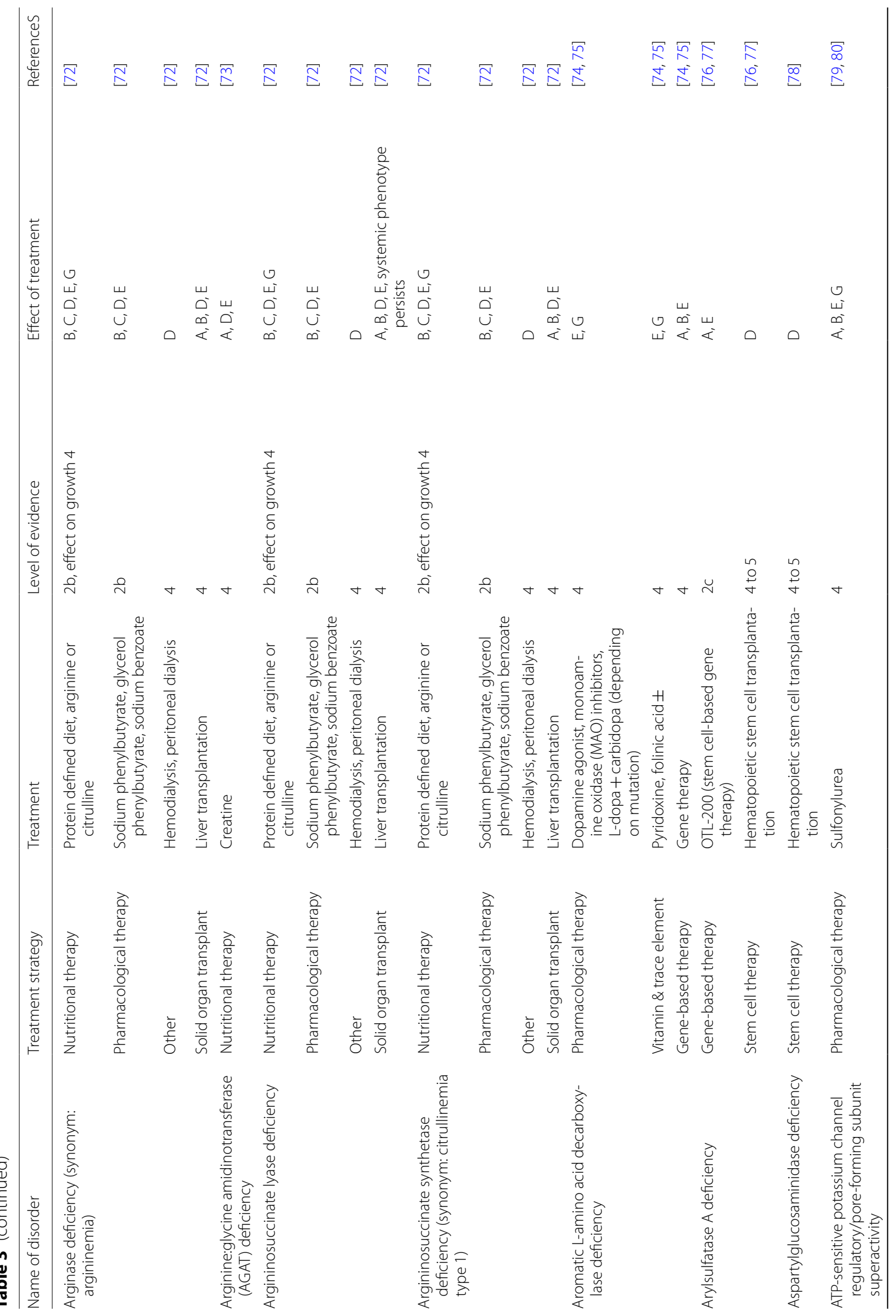




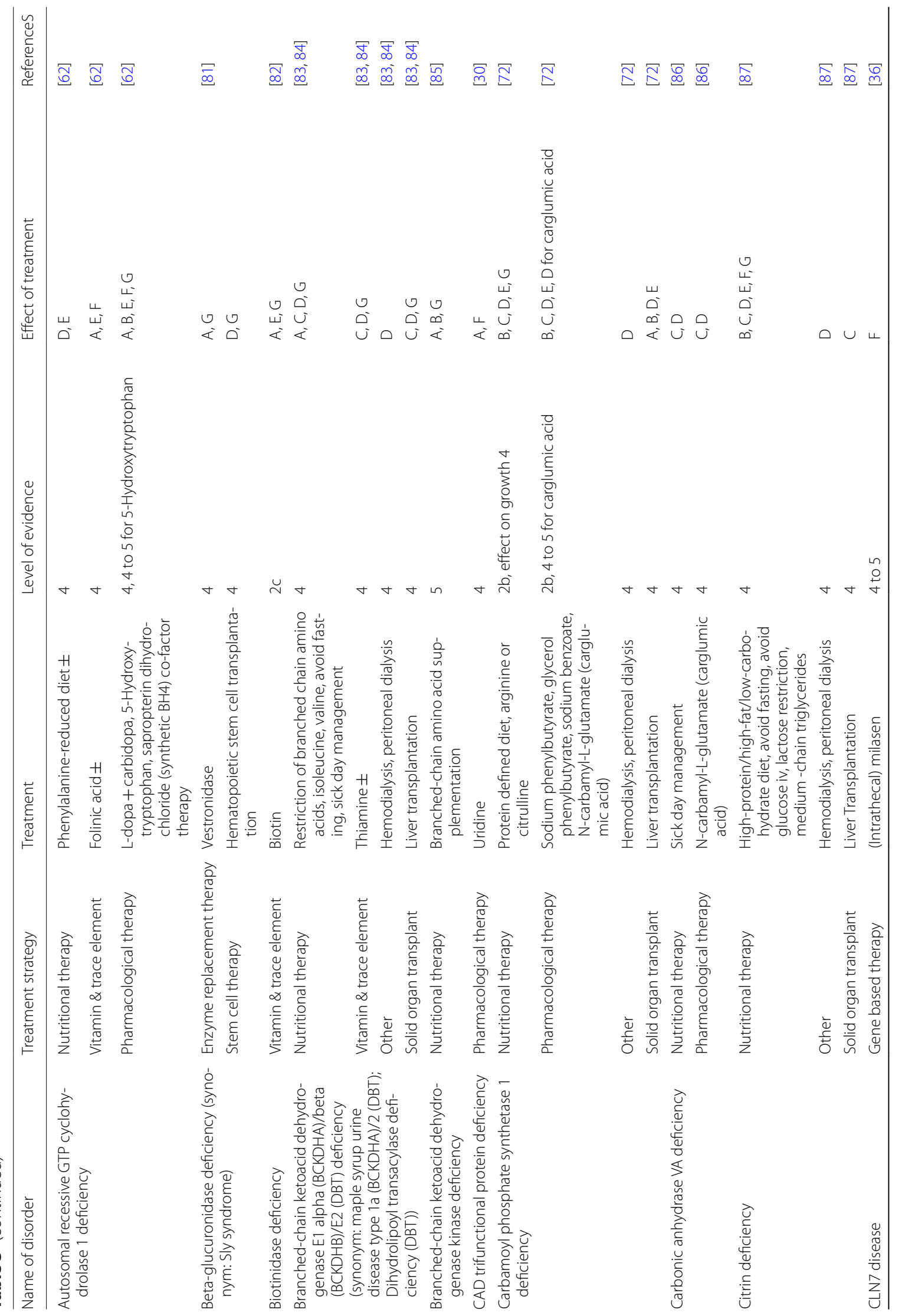




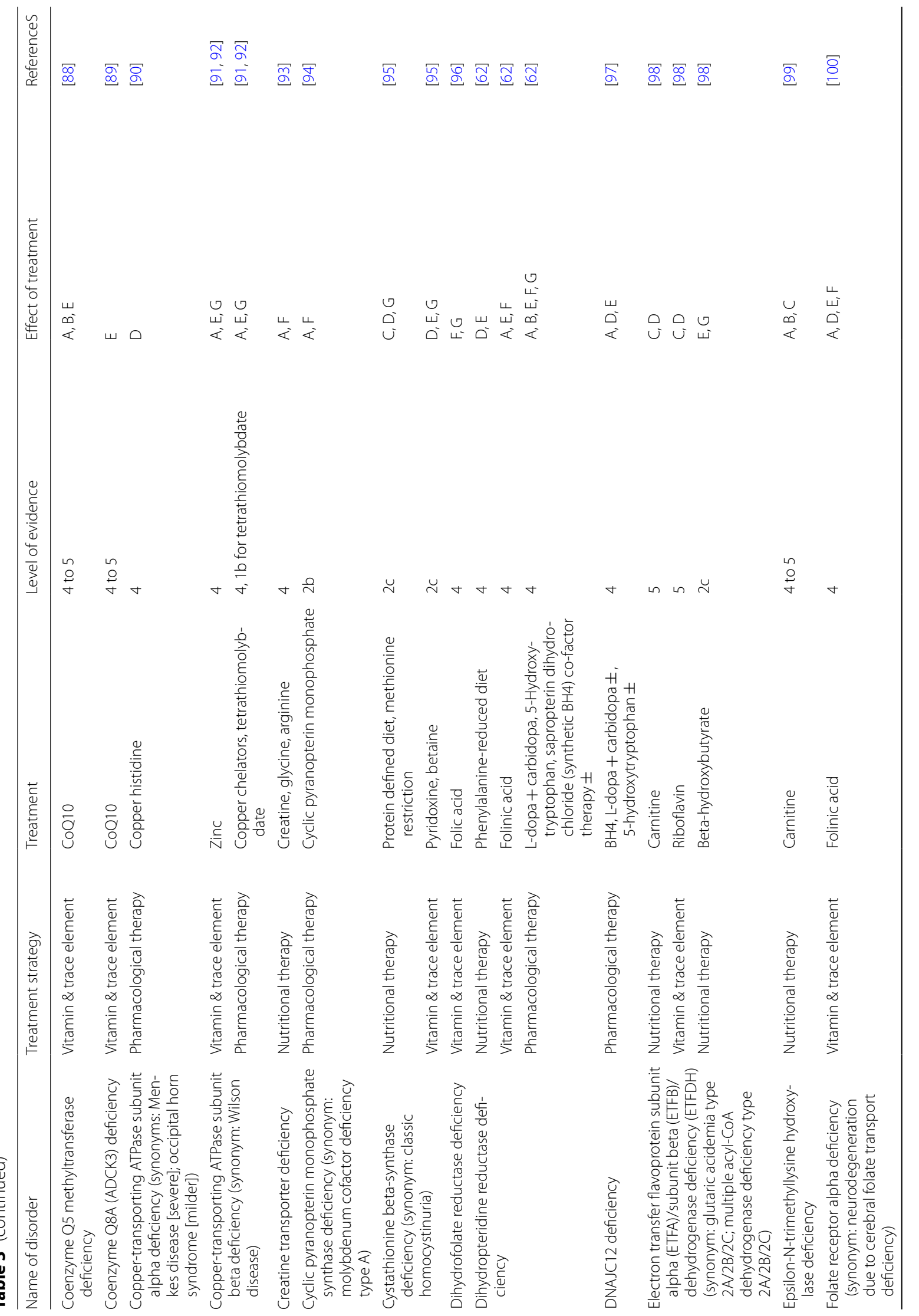




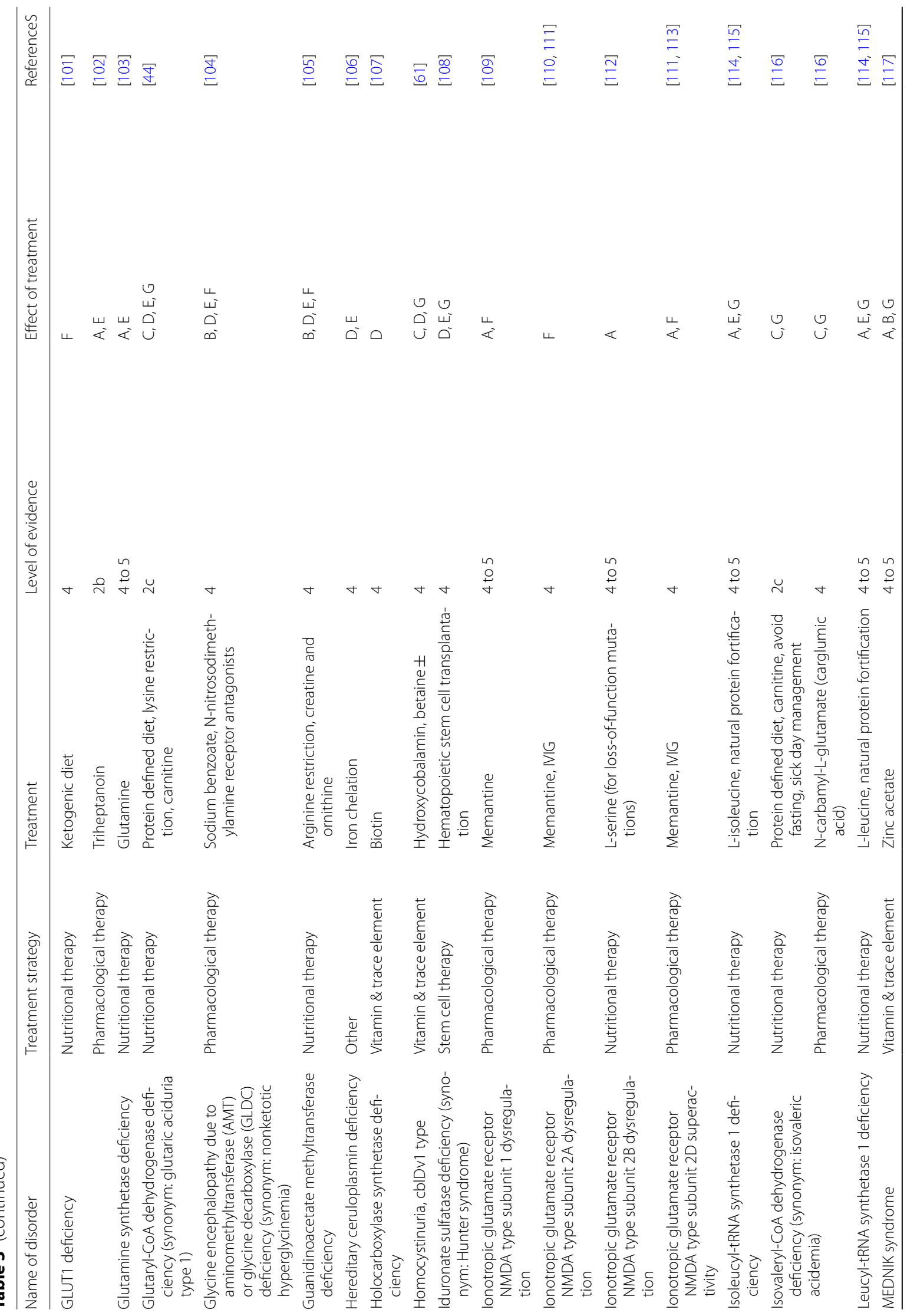




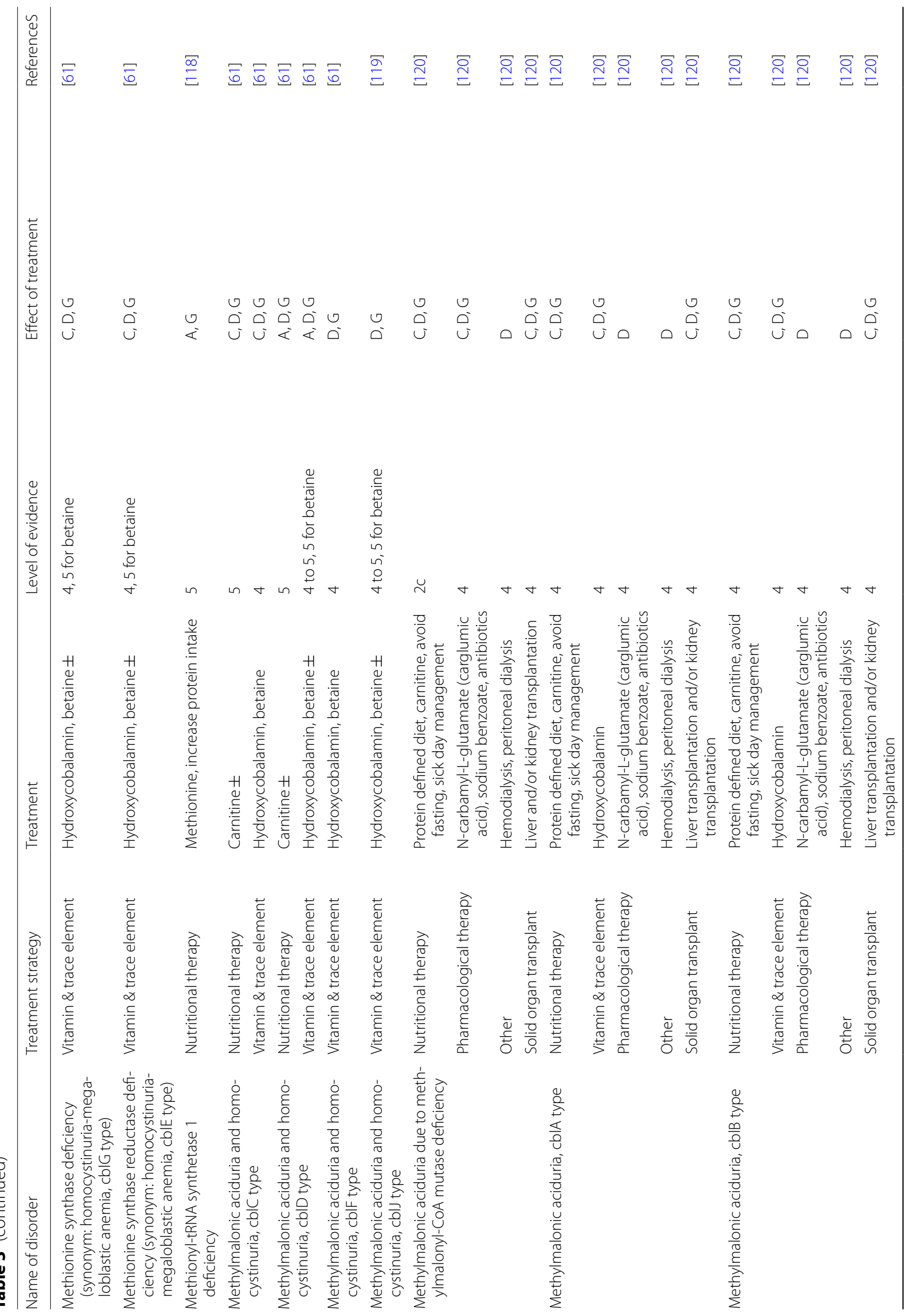




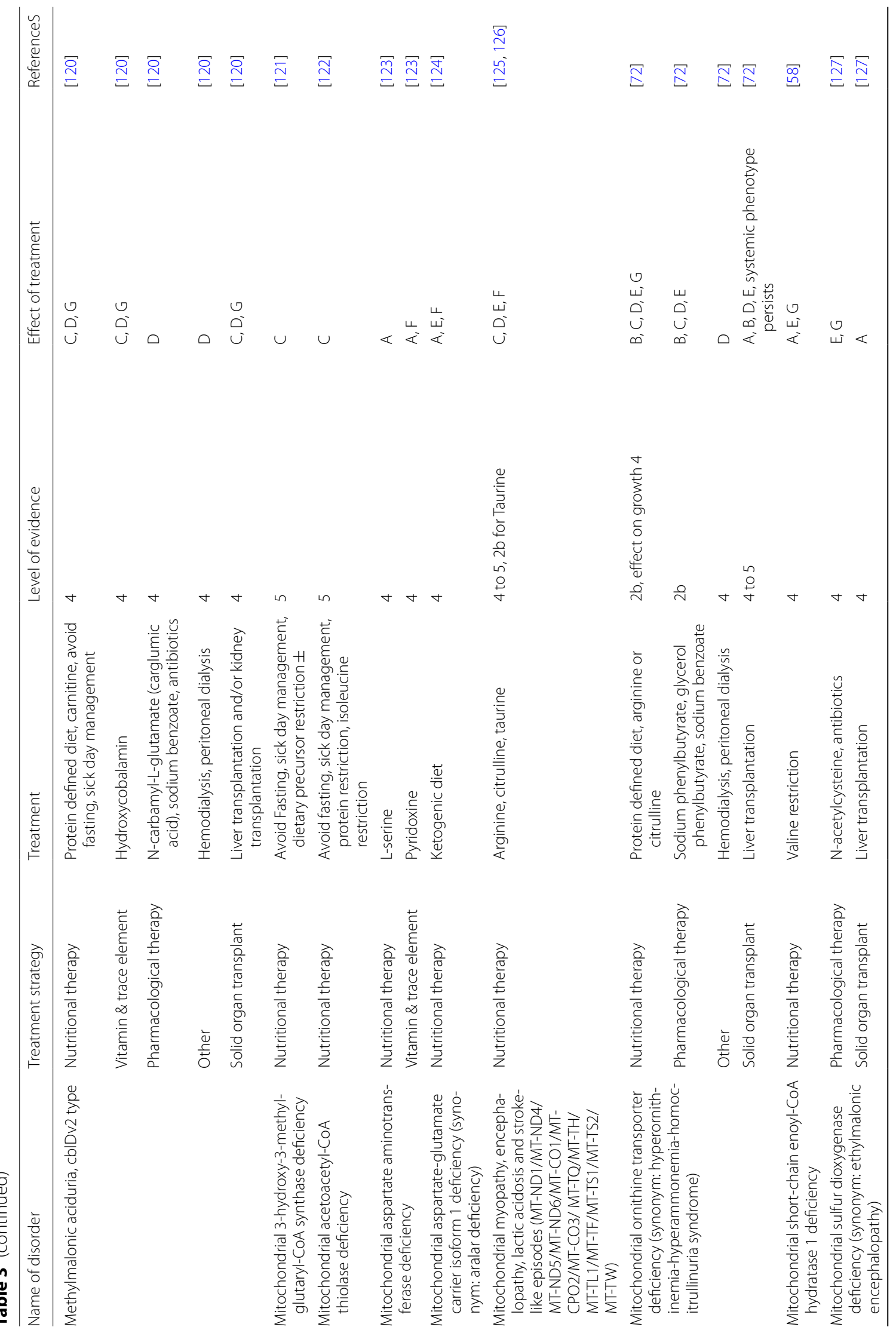




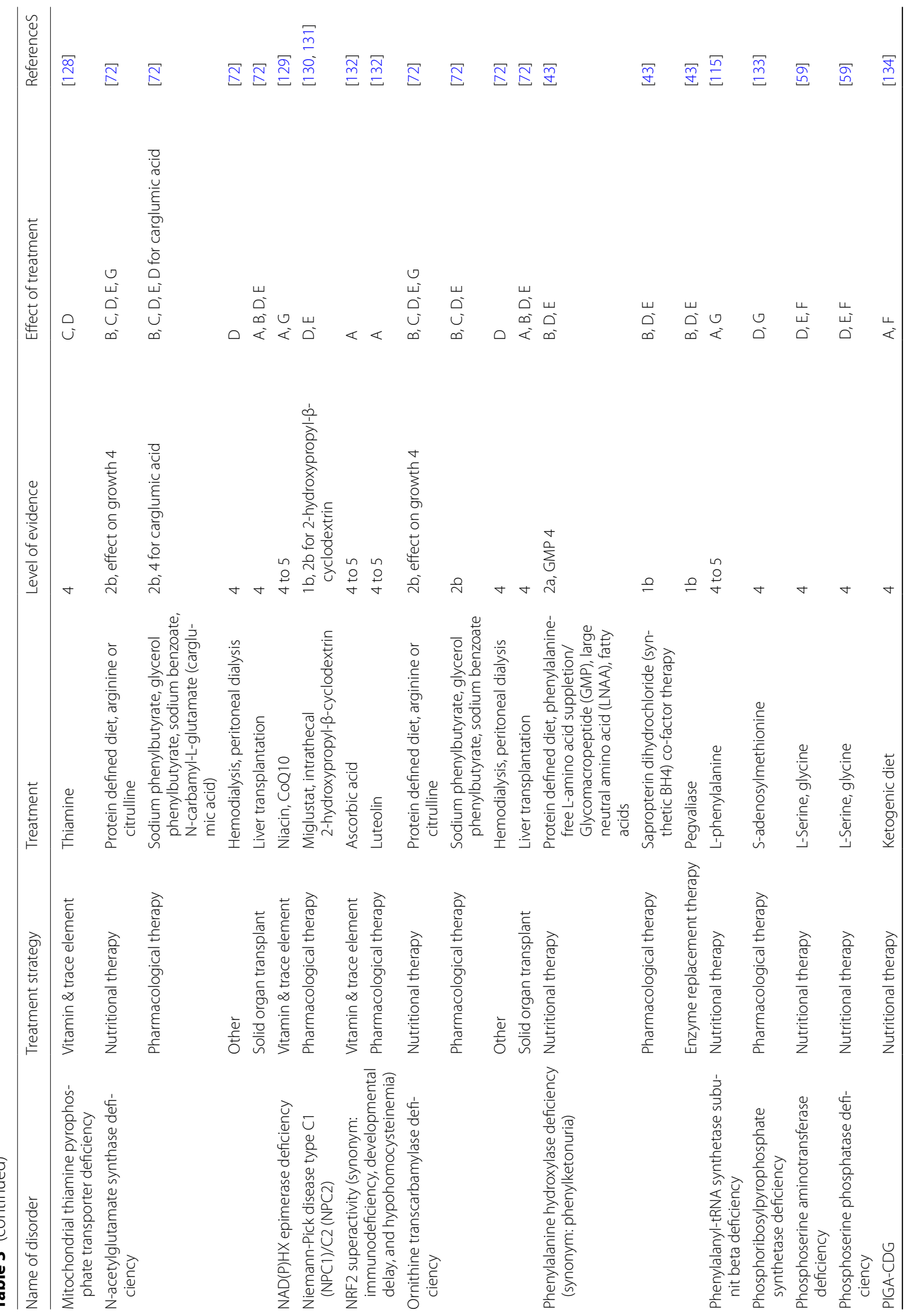




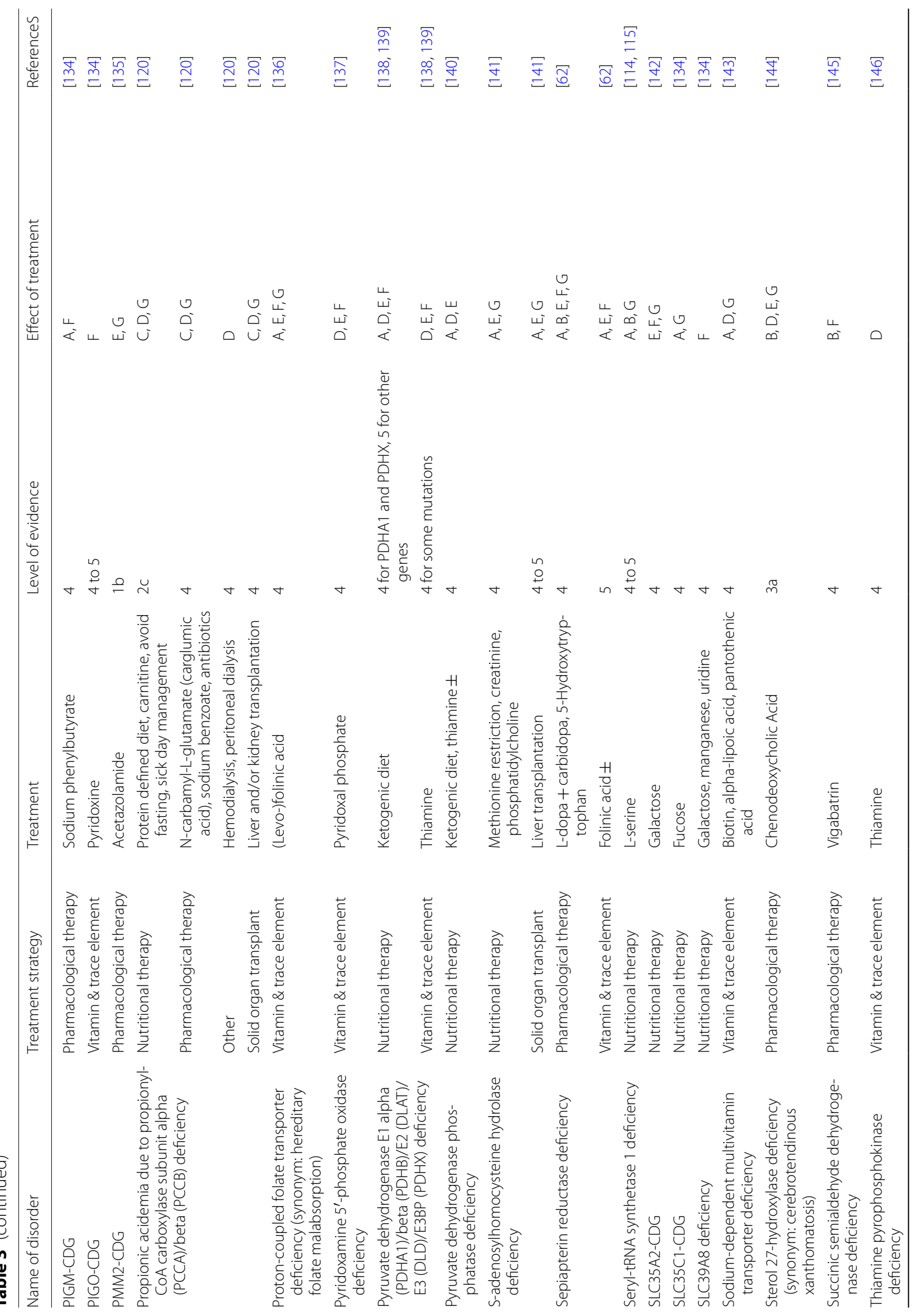




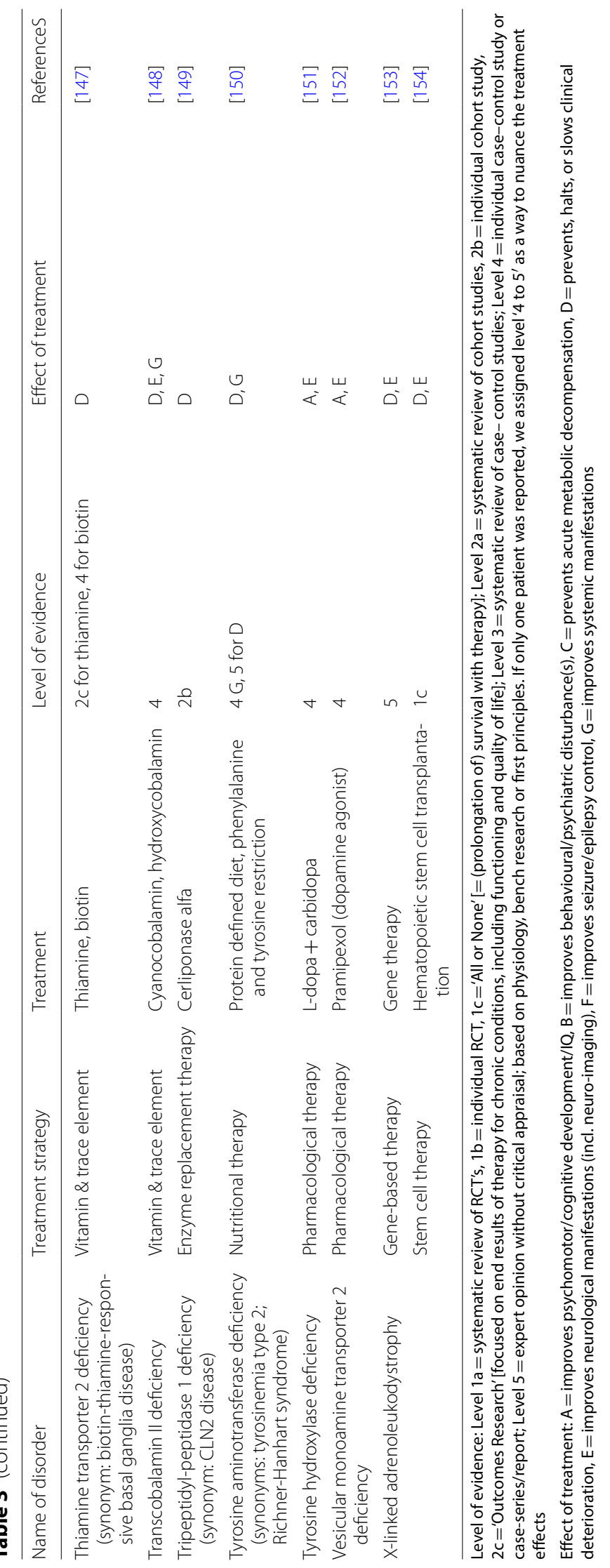




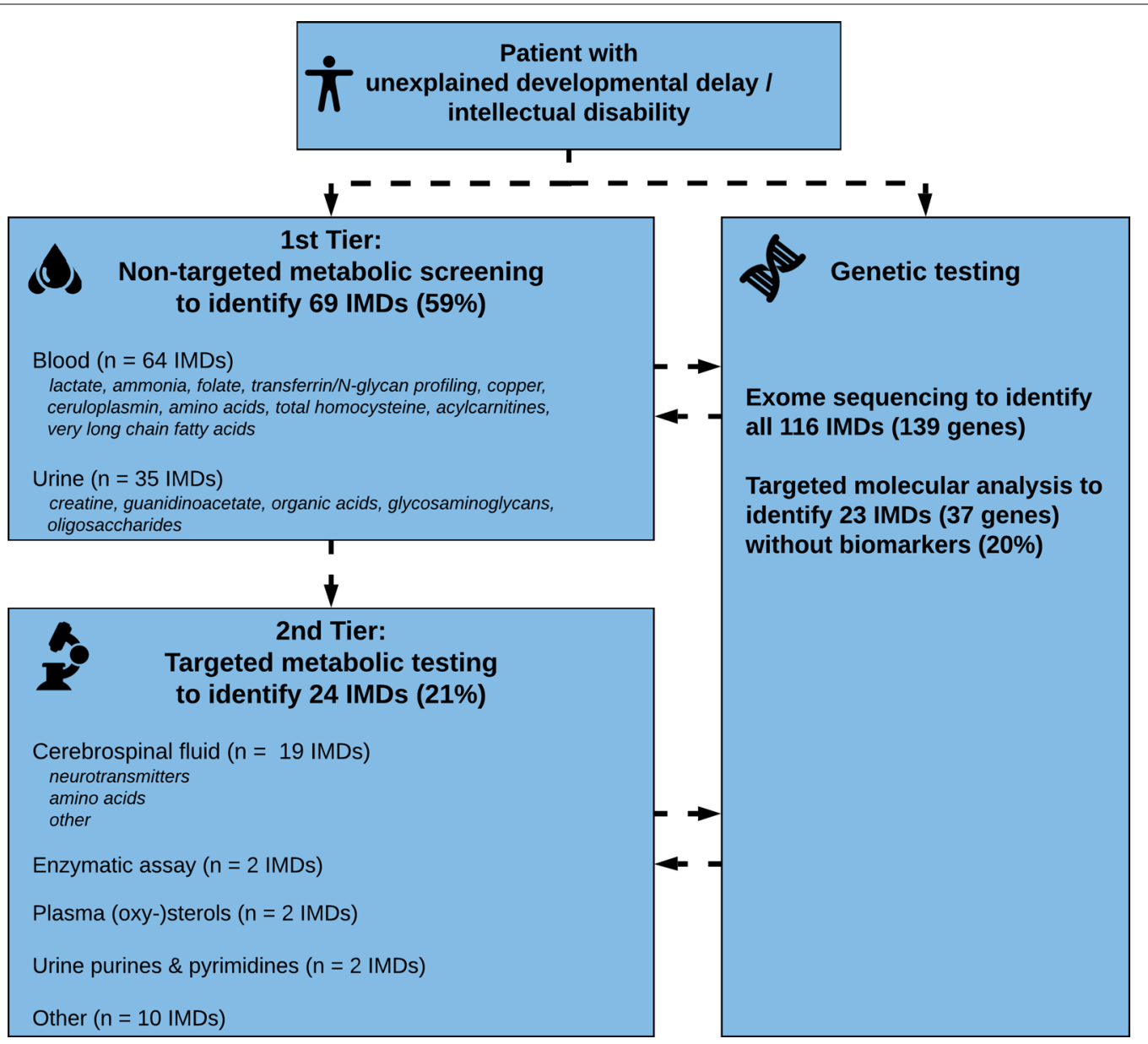

Fig. 1 Diagnostic algorithm for treatable IDs. 1st Tier consists of non-targeted metabolic screening tests that are readily available in most developed countries. 2 nd Tier consists of targeted metabolic tests, often more invasive and/or less available. Some IMDs are identified by multiple (screening) tests in the 1st and 2nd Tier. Genetic testing (targeted molecular analysis as well as exome sequencing) can be performed in parallel. $(\mathrm{ID}=$ Intellectual disability; $I \mathrm{MD}=$ Inherited Metabolic Disorder)

deficiency [30]), in turn leading to prioritization of exome sequencing (panels) in the diagnostic algorithm. However, these techniques are not always available or have significantly longer turnaround times than conventional metabolic screening in body fluids. Conversely, about $50 \%$ of all individuals undergoing genetic testing for ID remain without a diagnosis, which still makes metabolic screening an important part of the diagnostic workup. This is further underlined by a recent study on genomic newborn screening, showing that ES identifies only 9 out of 10 IMDs picked up reliably by tandem mass spectrometry. Thus picking up all patients eligible for early intervention urges a combined approach [31] The 1st and 2nd tier metabolic tests will also identify IDs not amenable to targeted therapy. Of course, any type of diagnosis is beneficial as it provides closure, end to a diagnostic odyssey, information to patients and families, as well as access to accurate genetic counseling, supportive care and reimbursement.

The exact order of diagnostic tests still depends on local resources and expertise and needs critical appraisal and personalization of the subsequent treatment itself. The diagnostic algorithm as shown in Fig. 1 is our recommendation, based on the yield of metabolic tests combined in the tiers, as well as availability at most if not all metabolic laboratories. The algorithm can be adapted according to the clinician's insights and laboratory specialist's expertise, as well as the patient's clinical phenotype (red flags) along with local laboratory resources.

Increasingly, metabolomics or next generation metabolomic screening (NGMS) will replace the individual biochemical tests and assays, similar to ES replacing single gene tests or panels [32]. Already today, most genetic laboratories solely work with ES and use virtual panels or virtual single gene analysis when these tests are required. 

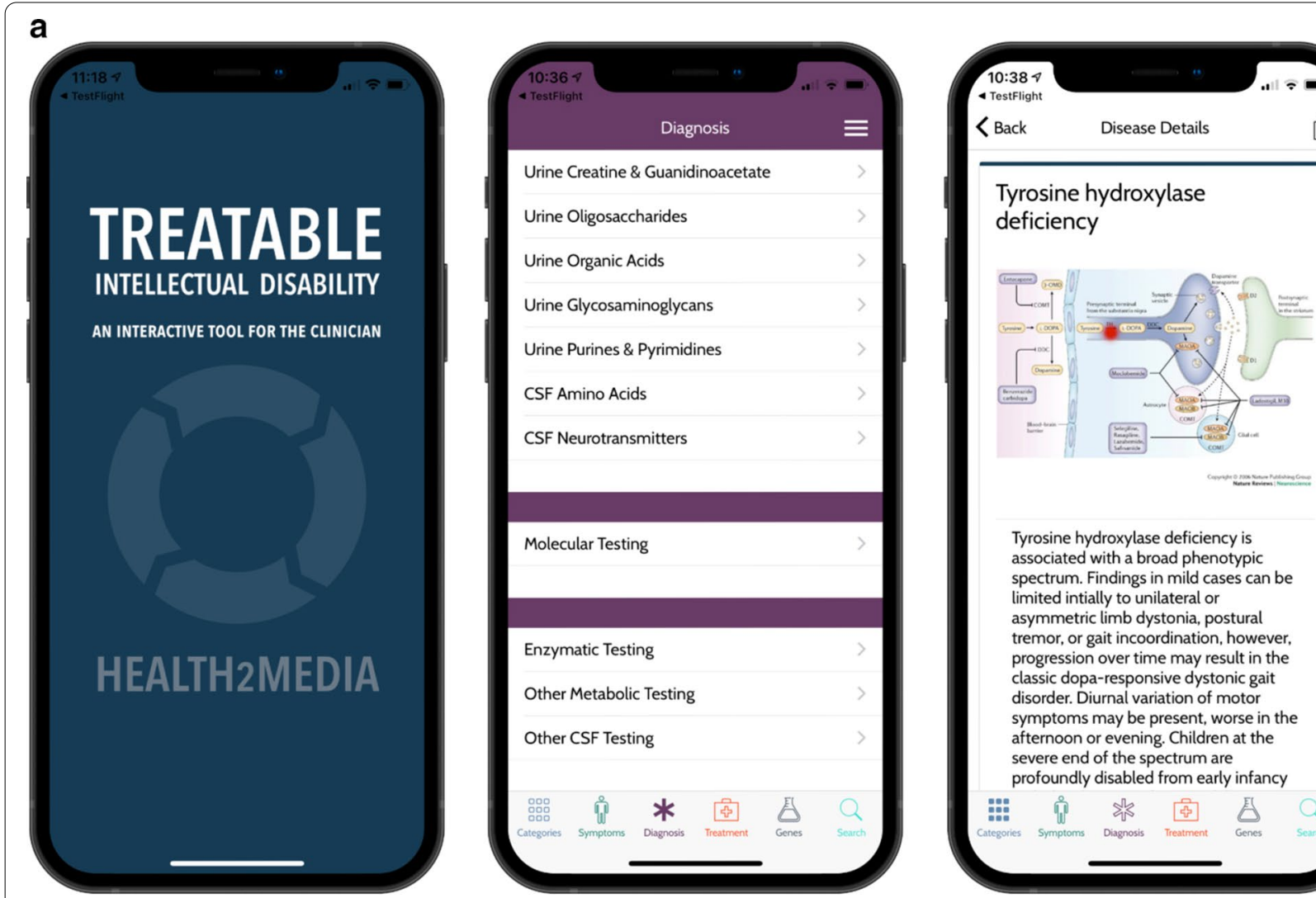

Tyrosine hydroxylase deficiency is associated with a broad phenotypic spectrum. Findings in mild cases can be limited intially to unilateral or

asymmetric limb dystonia, postural tremor, or gait incoordination, however. progression over time may result in the classic dopa-responsive dystonic gait disorder. Diurnal variation of motor

symptoms may be present, worse in the

afternoon or evening. Children at the

severe end of the spectrum are

profoundly disabled from early infancy

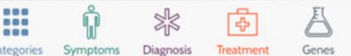

b

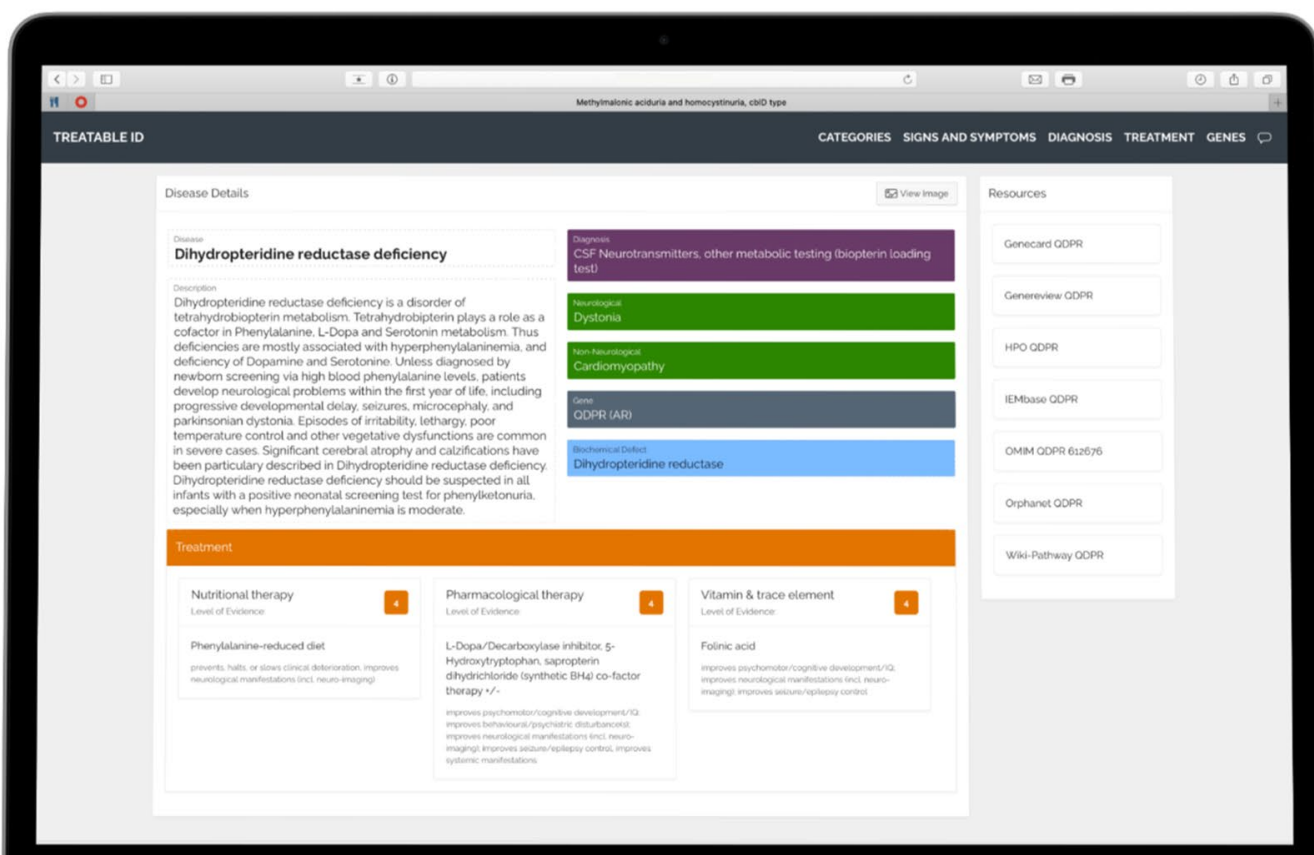

MacBook Pro

Fig. 2 The updated Treatable ID App, an interactive digital tool for the clinician to a search for IMDs according to genes, signs and symptoms, diagnostic tests, and treatments, and $\mathbf{b}$ find information on specific IMDs along with links to other digital resources. (IMD =Inherited Metabolic Disorder) 
Hence, in most clinical situations, it seems reasonable to initiate metabolic screening and genetic testing in parallel. The metabolic screening results can validate the functional impact of genetic variants identified by ES (eg N-acetyl-mannosamine for NANS-CDG [33]), thus providing a functional read-out. In ES negative patients, metabolic aberrations can help to guide the genetic investigations to scrutinize genes in specific pathways and vice versa, the genetic results can direct the NGMS interpretation and/or require additional specific metabolic testing (e.g., enzyme assays). In life-threatening situations or Progressive Intellectual and Neurologic Deterioration (PIND), quick turn-around is indicated for both metabolic/NGMS screening (within hours) and 'accelerated'/ 'Turbo' genome sequencing whenever available.

\section{Treatment advances}

In parallel, rare disease and (tailored) genetic therapies are gaining mainstream attention with the Food and Drug Administration (FDA) approval of the antisense oligonucleotide (Nusinersen) as well as the gene therapy (onasemnogene abeparvovec) for Spinal muscular atrophy (SMA) [34, 35] and the first personalized antisense oligonucleotide (Milasen) for CLN7-related neurodegeneration [36].

Our data show that although there has been much attention given to gene-based and enzyme replacement therapy, the majority of currently available, effective treatment strategies are nutritional, via dietary interventions and supplementation of vitamins and trace elements. These are relatively cheap, widely available, non-invasive and can be surprisingly effective.

Outcomes of disease and effect of treatment vary widely, depending on the IMD and therapy in question as well as the severity of the phenotype, the disease course and phase, the patient's age and co-morbidity as well as yet unknown factors. For some IMDs, timely and continued treatment ensures patients live (almost) normal lives, with Phenylketonuria (PKU) being the most prominent example. PKU is not only a superb example for a treatable ID managed with a 'classical' nutritional intervention to restrict the toxic substrate, but also how further research can broaden the therapeutic opportunities (e.g., tetrahydrobiopterin, Pegvaliase) and how the genotype can help in treatment planning.

We decided to exclude certain disorders where ID is no longer considered one of the main clinical features (e.g., Succinyl-CoA:3-oxoacid-CoA transferase (SCOT) deficiency, Riboflavin transporter deficiency (RTD)), or where treatment was shown to be ineffective in larger studies (e.g., Sanfilippo syndrome A-D). However, with the increasing focus on personalized treatment we realize that some therapies will show positive effects in selected individuals, while not meeting the "evidence-based" definition for group as a whole.

As our literature review shows, new disorders have been added to this list at a high pace, with 44 new disorders added since 2014. Representative examples include CAD trifunctional protein deficiency in which oral supplementation of uridine (monophosphate) has shown to dramatically improve epilepsy and enable psychomotor development [30, 37]; or memantine repurposing for the treatment of Ionotropic glutamate receptor NMDA type subunit 2A (GRIN2A) dysregulation. For other IMDs, even with treatment, patients still have very severe symptoms, with improvement of IQ seldom reported, but often with improvement of communication skills and behavior. Also, improvement of seizure frequency and intensity can be achieved. While data are scarce to prove the assumption that early treatment will lead to better outcomes, this still seems logical and should prompt the earliest possible diagnosis.

\section{Prioritizing treatable IMDs in the ID workup}

The systematic review of 2012 and its update in 2014 were the first evidence-based approach to demonstrate the significance of IMDs in the diagnostic work up of ID/DD. Whilst most recommendations for the diagnostic workup of DD/ID prioritize frequency of conditions and yield of diagnostic tests, our approach prioritized treatability over frequency and strategizes metabolic/biochemical evaluation in a two-tiered fashion. The utility of this approach was recently shown in the 7-year TIDE$\mathrm{BC}$ study, where we used the two-tiered TIDE diagnostic algorithm for treatable IMD detection superimposed onto current guidelines for the evaluation of unexplained ID. A total of 498 patients (63\% male) patients were enrolled; etiologic diagnoses were established in 260 patients $(52 \%)$, including treatable IMDs in $5 \%$, a third of whom presented with nonspecific symptoms not primarily suggestive of an IMD. Another 15 individuals were diagnosed with a non-treatable IEM [16]. This study represents the first comprehensive metabolic evaluation of a large cohort of patients with ID that is broadly representative of the population seen in a tertiary centre with a biochemical and genetic focus, and therefore possible bias towards IMD. The 29 treatable IMD cases identified and the high overall etiologic diagnosis rate demonstrate the clinical utility of overlaying the TIDE protocol onto current guidelines [16]. The results emphasize the importance of testing for treatable IEMs in all patients with unexplained ID, as earlier diagnosis provides the opportunity to mitigate or possibly prevent irreversible brain damage. Even IMDs for which the typical phenotype comprises complex neurologic abnormalities, PIND or multi-organ disease rather than isolated or stable ID, 
the earliest or presenting symptom is often developmental delay only (e.g. mucopolysaccharidoses) and thus applying the proposed algorithm and App broadly will enhance early pick-up and treatment of IMDs.

\section{Treatable ID App}

The updated Treatable ID App is designed to serve as an up-to-date, easily accessible and freely available digital tool for all clinicians and laboratory specialists evaluating children presenting with ID. Given the challenge of keeping up with clinical and scientific developments, possibly even more so for rare disorders, this app is meant to facilitate this process and translate the vast knowledgebase into a handy resource for early diagnosis and timely treatment. Searching based on signs and symptoms to generate a differential diagnosis and overviews of tests and treatments is a new feature. Also, a gene list for targeted exome analysis can be generated. The App is kept succinct in order to facilitate quick and easy use. Links are provided to more extensive databases, such as IEMbase [8], that provide more details on diagnostics and symptoms. This way, clinicians can easily access more information as needed. Obviously, the Treatable ID App will need to be updated regularly to reflect advances in the field. The current implementation is designed to facilitate this updating process, every 12 months.

\section{Limitations and improvements Treatobolome database}

The development of the 'treatabolome' database poses many challenges, especially with regard to curation, and will require expert input from both the clinical domain and the computational and data stewardship domain.

\section{Multi-omics to improve metabolic and genetic (newborn) screening}

Another ongoing challenge is the improvement of metabolic screening towards comprehensive tests (next generation metabolic screening, combining metabolomics, glycomics and lipidomics, etc.) [32]. This is in line with the needs to improve and extend genetic screening methods by adding mitochondrial DNA analysis from exome data, genome sequencing and RNA sequencing to the 'first tier' genetic toolbox [38] [39] [40]. The implementation of genetic screening into newborn screening programs together with metabolic screening is one of the ongoing challenges.

\section{Standardizing therapies and creating higher evidence levels}

Our literature search revealed several shortcomings (for a general review on this topic, the evidence creation in IMD, see Stockler-Ipsiroglu et al. [2]) that need to be addressed in the future. The evidence of the investigated literature is low. Guidelines, following methodologies established by Scottish Intercollegiate Guideline Network (SIGN) [41] and Grading of Recommendations, Assessment, Development and Evaluations (GRADE) [42] based on rigorous evidence rating and transparent grading of recommendations have become an important tool for the standardization of clinical management of IMDs. These are, however, only available for 13 of the $>1400$ known IMDs (e.g., for PKU [43], Glutaric aciduria I [44] or Cobalamin deficiencies [45]). This is reflected by our literature review identifying most often non-analytic case series or case reports with an evidence level of $4(60 \%)$, $4-5(12 \%)$ and $5(8 \%)$.

Because of the nature of rare disorders itself and the current trend to simultaneously develop (or better explore) different treatment modalities for single IMDs, alternative clinical trial designs with the ability to evaluate treatments in small populations within a short time are needed more than ever [46].

With the emergence of drug repurposing for personalized therapies, N-of-1 trials will be increasingly used for proof of principle studies in single patients. Such trial designs will address clinical heterogeneity [47], and incorporate personally meaningful outcomes reflecting patients' preferences and real world daily experience of the rare disease. In cases where clinical trials cannot be performed, registries with well-defined clinical endpoints can elevate the evidence created by registry-based trials. Adopting common data elements with standardized ontologies [48] as well as the agreement on core outcome sets, [49] is now considered a prerequisite for comparability of data collected across the medical systems caring for rare diseases patients.

\section{Access of patients to new technologies and treatments}

Our Treatable ID App and algorithm aligns with the vision of the International Rare Diseases Research Consortium to enable all people living with a rare disease to receive an accurate diagnosis and personalized care plan. However access to therapy is still a considerable hurdle in many parts of the world. European Reference Networks and designated centres of expertise address this medical gap. To 'leave no one behind, we encourage timely refer all diagnosed patients (at least once) to a such centre to enable access to therapeutic interventions as well as participation in clinical trials and other research studies. Expertise in compounding drugs and magistral preparations is essential for equitable access, as well as a voice in health policy on reimbursement of and access to (orphan) drug and nutritional therapy reimbursement [50] [51] [52]. 


\section{Conclusions}

Treatable IMDs are a moving target. The broad implementation of next-generation genomic and metabolomic testing in daily clinical practice has accelerated the diagnostics for many individuals with ID. In parallel, the increasing knowledge about the genetic basis of disease, insights into pathophysiology, and advances in therapeutic and targeting strategies catalyze the Treatabolome as a whole; this is true as well for IMDs causing ID. At the same time, methods for evidence generation with small patient numbers as well as more extensive and longerterm follow-up studies will reveal that some therapeutic interventions initially deemed effective do not alter primary or secondary outcomes. These exciting developments require continuous updates of the Treatable ID App, the Treatabolome database, as well as other digital resources. In parallel, diagnostic protocols-whether metabolic or genomic-should also be adjusted to prioritize treatable conditions in the diagnostic workup of suspected IMDs and ensure the earliest possible intervention. We encourage clinicians to use our App to facilitate diagnosis and intervention for treatable IDs, and welcome all feedback including treatable IDs we may have missed.

\section{Abbreviations}

ES: Exome sequencing; DD: Global developmental delay; IMD: Inherited metabolic disorder; ICIMD: International classification of inherited metabolic disorders; ID: Intellectual disability; CSF: Cerebrospinal fluid; HVA: Homovanillic acid; NGS: Next generation sequencing; NGMS: Next generation metabolomic screening; PIND: Progressive intellectual and neurologic deterioration; SMA: Spinal muscular atrophy; PKU: Phenylketonuria; COS: Core outcome measure set.

\section{Supplementary Information}

The online version contains supplementary material available at https://doi. org/10.1186/s13023-021-01727-2.

Additional File 1. Inherited metabolic disorders (IMDs) included in our 2012 (PMID 22212131) and 2014 (PMID 24518794) reviews and currently excluded.

\section{Acknowledgments}

The authors are grateful to the patients and families for daily teaching and inspiration, to the clinical and scientific colleagues for all their efforts to advance diagnosis and treatment of IMDs and finally to Mr Jeff Joa (Vancouver) for his technical contribution to the App.

\section{Authors' contributions}

EHvK performed the literature review, critical assessment and data extraction, participated in consensus meetings, drafted and edited the manuscript. SW performed the literature review, critical assessment and data extraction, participated in consensus meetings, drafted and edited the manuscript. MK contributed to the literature review and critical assessment, performed data extraction, participated in consensus meetings and edited the manuscript. LT contributed to the literature review and critical assessment, and revised the manuscript. $\mathrm{RH}$ contributed to review data translation and Treatable ID App design with feature updates, and contributed to the App sections of the manuscript. SS performed the initial systematic review on treatable IDs and the initial version of the App, critical assessment of data, and edited the current version of the manuscript. CF contributed to the literature review, performed data extraction and critical assessment, participated in consensus meetings and revised the manuscript. CvK designed study, supervised the literature review, critical assessment and data extraction, participated in consensus meetings, translated and prepared data for the App, drafted and edited the manuscript. All authors approved the final version of the manuscript.

\section{Funding}

CVK is supported by a salary award from 'Stichting Metakids' in The Netherlands. SW is supported by ERAPERMED2019-310-Personalized Mitochondrial Medicine (PerMiM) and FWF Jubiläumsfondprojekt Nr. 18023.

\section{Availability of data and materials}

All data generated and analyzed during this study are included in this published article, the supplementary information files and the Treatable ID app (www. Treatable-id.org). The literature search and data are available upon request.

\section{Ethics approval and consent to participate}

Not applicable.

\section{Consent for publication}

Not applicable.

\section{Competing interests}

The authors declare that they have no competing interests.

\section{Author details}

${ }^{1}$ Department of Pediatrics, Amsterdam UMC, Amsterdam, The Netherlands. 2 Department of Pediatrics, Radboud Center for Mitochondrial Medicine, Radboud University Medical Center, Nijmegen, The Netherlands. ${ }^{3}$ University Children's Hospital, Paracelsus Medical University, Salzburg, Austria. ${ }^{4}$ On Behalf of United for Metabolic Diseases, Amsterdam, The Netherlands. ${ }^{5}$ Division of Biochemical Diseases, Department of Pediatrics, BC Children's Hospital, Vancouver, BC V6H 3V4, Canada. ${ }^{6}$ Health2Media, Amsterdam, The Netherlands. ${ }^{7}$ National Human Genome Research Institute, National Institutes of Health, Bethesda, MD, USA. ${ }^{8}$ Department of Pediatrics - Metabolic Diseases, Amalia Children's Hospital, Geert Grooteplein 10, Radboud University Medical Center, 6525 GA Nijmegen, The Netherlands.

Received: 23 December 2020 Accepted: 3 February 2021

Published online: 12 April 2021

\section{References}

1. van Karnebeek CDM, Wortmann SB, Tarailo-Graovac M, Langeveld M, Ferreira CR, van de Kamp JM, et al. The role of the clinician in the multiomics era: are you ready? J Inherit Metab Dis. 2018;41:571-82.

2. Stockler-Ipsiroglu S, Potter BK, Yuskiv N, Tingley K, Patterson M, Karnebeek C. Developments in evidence creation for treatments of inborn errors of metabolism. J Inherit Metab Dis. 2020;jimd.12315.

3. van Karnebeek CDM, Stockler S. Treatable inborn errors of metabolism causing intellectual disability: A systematic literature review. 2012;105:368-81.

4. van Karnebeek CDM, Shevell M, Zschocke J, Moeschler JB, Stockler S. The metabolic evaluation of the child with an intellectual developmental disorder: diagnostic algorithm for identification of treatable causes and new digital resource. Mol Genet Metab. 2014;111:428-38.

5. International joint recommendations to address specific needs of undiagnosed rare disease patients. SWAN UK (the support group run by Genetic Alliance UK), the Wilhelm Foundation, EURORDIS (Rare Diseases Europe), Rare Voices Australia (RVA), the Canadian Organization for Rare Disorders (CORD), the Advocacy Service for Rare and Intractable Diseases' stakeholders in Japan (ASrid) and the National Organization for Rare Disorders (NORD). http://download2.eurordis.org.s3.amazonaws. com/documents/pdf/Undiagnosed-International-Joint-Recommenda tions.pdf. Accessed 23 Dec 2020. 
6. Morava E, Rahman S, Peters V, Baumgartner MR, Patterson M, Zschocke J. Quo vadis: the re-definition of "inborn metabolic diseases." J Inherit Metab Dis. 2015;38:1003-6.

7. International Classification of Inherited Metabolic Disorders (ICIMD). http://www.icimd.org. Accessed 10 Dec 2020.

8. Inborn Errors of Metabolism Knowledgebase (IEMbase). www.IEMbase. org. Accessed 10 Dec 2020.

9. Moeschler JB, Shevell M. Comprehensive evaluation of the child with intellectual disability or global developmental delays. Pediatrics. 2014;134:e903-18.

10. Bélanger SA, Caron J. Evaluation of the child with global developmental delay and intellectual disability. Paediatr Child Health. 2018;23:403-10.

11. van den Elzen A. NVK richtlijn Ontwikkelingsachterstand/verstandelijke beperking. 2018. https://www.nvk.nl/themas/kwaliteit/richtlijnen/richt lijn?componentid=7667712\&tagtitles=Erfelijke\%2Ben\%2Baangebor en\%2Baandoeningen,Metabole\%2BZiekten,Keel-Neus-Oog\%2B(KNO) ,Neurologie. Accessed 10 Dec 2020.

12. van Karnebeek CDM, Houben RFA, Lafek M, Giannasi W, Stockler S The treatable intellectual disability APP www.treatable-id.org: A digital tool to enhance diagnosis \& care for rare diseases. Orphanet J Rare Dis. 2012;7:47.

13. Van Karnebeek CDM. Evaluation of the child with developmental impairments. Contin Lifelong Learn. Neurol. 2018.

14. van Karnebeek CD, Stockler-Ipsiroglu S. Early identification of treatable inborn errors of metabolism in children with intellectual disability: The Treatable Intellectual Disability Endeavor protocol in British Columbia. Paediatr Child Health. 2014;19:469-71.

15. Sayson B, Popurs MAM, Lafek M, Berkow R, Stockler-Ipsiroglu S, van Karnebeek CDM. Retrospective analysis supports algorithm as efficient diagnostic approach to treatable intellectual developmental disabilities. Mol Genet Metab. 2015;115:1-9.

16. van Karnebeek, Clara D.M.; Dragojlovic, Nick; Sinclair, Graham; Salvarinova, Ramona; Horvath, Gabriella; Selby, Katherine; Ghani A et al. The TIDE study: treatable inherited metabolic disorders identified in a cohort of 498 children with unexplained intellectual developmental disorder. Submitted.

17. van Karnebeek CDM, Sayson B, Lee JJY, Tseng LA, Blau N, Horvath GA, et al. Metabolic evaluation of epilepsy: a diagnostic algorithm with focus on treatable conditions. Front Neurol. 2018;9:1016.

18. Hillert A, Anikster Y, Belanger-Quintana A, Burlina A, Burton BK, Carducc $C$, et al. The genetic landscape and epidemiology of phenylketonuria. Am J Hum Genet. 2020;107:234-50.

19. Shen JJ, Wortmann SB, de Boer L, Kluijtmans LAJ, Huigen MCDG, Koch $\mathrm{J}$, et al. The role of clinical response to treatment in determining pathogenicity of genomic variants. Genet Med. 2020.

20. Atalaia A, Thompson R, Corvo A, Carmody L, Piscia D, Matalonga L, et al. A guide to writing systematic reviews of rare disease treatments to generate FAIR-compliant datasets: Building a Treatabolome. Orphanet $J$ Rare Dis. 2020.

21. Orphanet. http://www.orpha.net/consor/cgi-bin/index.php?lng=EN. Accessed 10 Dec 2020.

22. Online Mendelian Inheritance in Man (OMIM). http://www.omim.org. Accessed 10 Dec 2020

23. Wilkinson MD, Dumontier M, Aalbersberg lj, Appleton G, Axton M, Baak A, et al. The FAIR Guiding Principles for scientific data management and stewardship. Sci Data. 2016;3:160018.

24. Wanders RJA, Vaz FM, Ferdinandusse $S$, van Kuilenburg ABP, Kemp $S$, van Karnebeek CD, et al. Translational Metabolism: A multidisciplinary approach towards precision diagnosis of inborn errors of metabolism in the omics era. J. Inherit. Metab. Dis. 2019.

25. Metakids. http://www.metakids.nl. Accessed 10 Dec 2020

26. Warmerdam HAG, Termeulen-Ferreira EA, Tseng LA, Lee JY, van Eeghen $A M$, Ferreira CR, et al. A scoping review of inborn errors of metabolism causing progressive intellectual and neurologic deterioration (PIND). Front Neurol. 2020.

27. Horvath GA, Tarailo-Graovac M, Bartel T, Race S, Van Allen MI, BlydtHansen I, et al. Improvement of self-injury with dopamine and serotonin replacement therapy in a patient with a hemizygous PAK3 mutation: a new therapeutic strategy for neuropsychiatric features of an intellectual disability syndrome. J Child Neurol. 2018;33:106-13.
28. Thompson R, Bonne G, Missier P, Lochmüller H. Targeted therapies for congenital myasthenic syndromes: Systematic review and steps towards a treatabolome. Emerg Top Life Sci. 2019;3:19-37.

29. Ebrahimi-Fakhari D, Van Karnebeek C, Münchau A. Movement disorders in treatable inborn errors of metabolism. Mov Disord. 2019;34:598-613.

30. Koch J, Mayr JA, Alhaddad B, Rauscher C, Bierau J, Kovacs-Nagy R, et al. CAD mutations and uridine-responsive epileptic encephalopathy. Brain [Internet]. 2017;140:279-86.

31. Adhikari AN, Gallagher RC, Wang Y, Currier RJ, Amatuni G, Bassaganyas $\mathrm{L}$, et al. The role of exome sequencing in newborn screening for inborn errors of metabolism. Nat Med. 2020;26:1392-7.

32. Coene KLM, Kluijtmans LAJ, van der Heeft E, Engelke UFH, de Boer S, Hoegen $B$, et al. Next-generation metabolic screening: targeted and untargeted metabolomics for the diagnosis of inborn errors of metabolism in individual patients. J Inherit Metab Dis. 2018;41:337-53.

33. Van Karnebeek CDM, Bonafé L, Wen XY, Tarailo-Graovac M, Balzano $\mathrm{S}$, Royer-Bertrand B, et al. NANS-mediated synthesis of sialic acid is required for brain and skeletal development. Nat Genet. 2016;48:777-84.

34. Hoy SM. Nusinersen: first global approval. Drugs. 2017;77:473-9.

35. Hoy SM. Onasemnogene Abeparvovec: first global approval. Drugs. 2019:79:1255-62.

36. Kim J, Hu C, Moufawad E, Achkar C, Black LE, Douville J, Larson A, et al. Patient-customized oligonucleotide therapy for a rare genetic disease. N Engl J Med. 2019;381:1644-52.

37. Rymen D, Lindhout M, Spanou M, Ashrafzadeh F, Benkel I, Betzler C, et al. Expanding the clinical and genetic spectrum of CAD deficiency: an epileptic encephalopathy treatable with uridine supplementation. Genet Med. 2020;22:1589-97.

38. Kremer LS, Wortmann SB, Prokisch H. "Transcriptomics": molecular diagnosis of inborn errors of metabolism via RNA-sequencing. J Inherit Metab Dis. 2018;41:525-32.

39. Wagner M, Berutti R, Lorenz-Depiereux B, Graf E, Eckstein G, Mayr JA, et al. Mitochondrial DNA mutation analysis from exome sequencingA more holistic approach in diagnostics of suspected mitochondrial disease. J Inherit Metab Dis. 2019;42:909-17.

40. Riley LG, Cowley MJ, Gayevskiy V, Minoche AE, Puttick C, Thorburn DR, et al. The diagnostic utility of genome sequencing in a pediatric cohort with suspected mitochondrial disease. Genet Med. 2020;22:1254-61.

41. Harbour R, Miller J. A new system for grading recommendations in evidence based guidelines. Br Med J. 2001;323:334-6.

42. Guyatt GH, Oxman AD, Vist GE, Kunz R, Falck-Ytter Y, Alonso-Coello P, et al. GRADE: an emerging consensus on rating quality of evidence and strength of recommendations. BMJ. 2008:336:924-6.

43. van Wegberg AMJ, MacDonald A, Ahring K, Bélanger-Quintana A, Blau $\mathrm{N}$, Bosch AM, et al. The complete European guidelines on phenylketonuria: diagnosis and treatment. Orphanet J Rare Dis. 2017;12:162.

44. Boy N, Mühlhausen C, Maier EM, Heringer J, Assmann B, Burgard P, et al. Proposed recommendations for diagnosing and managing individuals with glutaric aciduria type I: second revision. J Inherit Metab Dis. 2017:40:75-101.

45. Huemer M, Diodato D, Schwahn B, Schiff M, Bandeira A, Benoist JF, et al. Guidelines for diagnosis and management of the cobalamin-related remethylation disorders $\mathrm{cblC}, \mathrm{cblD}, \mathrm{cblE}, \mathrm{cblF}, \mathrm{cblG}, \mathrm{cblJ}$ and MTHFR deficiency. J Inherit Metab Dis. 2017:40:21-48.

46. Tingley K, Coyle D, Graham ID, Sikora L, Chakraborty P, Wilson K, et al. Using a meta-narrative literature review and focus groups with key stakeholders to identify perceived challenges and solutions for generating robust evidence on the effectiveness of treatments for rare diseases. Orphanet J Rare Dis. 2018;13:104.

47. Shamseer L, Sampson M, Bukutu C, Schmid CH, Nikles J, Tate R, et al. CONSORT extension for reporting N-of-1 trials (CENT) 2015: explanation and elaboration. J Clin Epidemiol. 2016;76:18-46.

48. Köhler S, Vasilevsky NA, Engelstad M, Foster E, McMurry J, Aymé S, et al. The human phenotype ontology in 2017. Nucleic Acids Res. 2017:45:D865-76.

49. Rubinstein YR, McInnes P. NIH/NCATS/GRDR ${ }^{\circledR}$ Common Data Elements: a leading force for standardized data collection. Contemp Clin Trials. 2015;42:78-80. 
50. Stawowczyk E, Malinowski KP, Kawalec P, Bobiński R, Siwiec J, Panteli D, et al. Reimbursement status and recommendations related to orphan drugs in European Countries. Front Pharmacol. 2019;10.

51. Dooms M, Carvalho M. Compounded medication for patients with rare diseases. Orphanet J Rare Dis. 2018;13:1.

52. Dooms M, Killick J. Off-label use of medicines: the need for good practice guidelines. Int J Risk Saf Med. 2017;29:17-23.

53. Shevell MI. Present conceptualization of early childhood neurodevelopmental disabilities. J Child Neurol. 2010;25:120-6.

54. Luckasson R, Reeve A. Naming, defining, and classifying in mental retardation. Ment Retard. 2001;39:47-52.

55. Shevell M. Global developmental delay and mental retardation or intellectual disability: conceptualization, evaluation, and etiology. Pediatr Clin North Am. 2008;55:1071-84.

56. Pubmed. https://pubmed.ncbi.nlm.nih.gov. Accessed 10 Dec 2020.

57. Grünert SC, Schlatter SM, Schmitt RN, Gemperle-Britschgi C, Mrázová L, Balcı MC, et al. 3-Hydroxy-3-methylglutaryl-coenzyme A lyase deficiency: clinical presentation and outcome in a series of 37 patients. Mol Genet Metab. 2017;121:206-15.

58. Abdenur JE, Sowa M, Simon M, Steenari M, Skaar J, Eftekharian S, et al. Medical nutrition therapy in patients with $\mathrm{HIBCH}$ and ECHS1 defects: clinical and biochemical response to low valine diet. Mol Genet Metab Reports. 2020;24:100617.

59. van der Crabben SN, Verhoeven-Duif NM, Brilstra EH, Van Maldergem L, Coskun T, Rubio-Gozalbo E, et al. An update on serine deficiency disorders. J Inherit Metab Dis. 2013;36:613-9.

60. Rodan LH, Qi W, Ducker GS, Demirbas D, Laine R, Yang E, et al. 5,10-methenyltetrahydrofolate synthetase deficiency causes a neurometabolic disorder associated with microcephaly, epilepsy, and cerebral hypomyelination. Mol Genet Metab. 2018;125:118-26.

61. Huemer M, Baumgartner MR. The clinical presentation of cobalaminrelated disorders: from acquired deficiencies to inborn errors of absorption and intracellular pathways. J Inherit Metab Dis. 2019:42:686-705.

62. Opladen T, López-Laso E, Cortès-Saladelafont E, Pearson TS, Sivri $\mathrm{HS}$, Yildiz Y, et al. Consensus guideline for the diagnosis and treatment of tetrahydrobiopterin (BH4) deficiencies. Orphanet J Rare Dis. 2020;15:126.

63. Wassif CA, Kratz L, Sparks SE, Wheeler C, Bianconi S, Gropman A, et al. A placebo-controlled trial of simvastatin therapy in Smith-Lemli-Opitz syndrome. Genet Med. 2017;19:297-305.

64. Bianconi SE, Cross JL, Wassif CA, Porter FD. Pathogenesis, epidemiology, diagnosis and clinical aspects of Smith-Lemli-Opitz syndrome. Expert Opin Orphan Drugs. 2015;3:267-80.

65. Repp BM, Mastantuono E, Alston CL, Schiff M, Haack TB, Rötig A, et al. Clinical, biochemical and genetic spectrum of 70 patients with ACAD9 deficiency: is riboflavin supplementation effective? Orphanet J Rare Dis. 2018;13:120.

66. Coughlin CR, van Karnebeek CDM, Al-Hertani W, Shuen AY, Jaggumantri $\mathrm{S}$, Jack RM, et al. Triple therapy with pyridoxine, arginine supplementation and dietary lysine restriction in pyridoxine-dependent epilepsy: Neurodevelopmental outcome. Mol Genet Metab. 2015;116:35-43.

67. Jiang $M$, Liu S, Jiang H, Lin Y, Shao $Y$, Hu H, et al. Brain abnormalities in fucosidosis: transplantation or supportive therapy? Metab Brain Dis. 2017;32:317-20.

68. Eisengart JB, Pierpont El, Kaizer AM, Rudser KD, King KE, Pasquali M, et al. Intrathecal enzyme replacement for Hurler syndrome: biomarker association with neurocognitive outcomes. Genet Med. 2019;21:2552-60.

69. Aldenhoven M, Wynn RF, Orchard PJ, O'Meara A, Veys P, Fischer A, et al. Long-term outcome of Hurler syndrome patients after hematopoietic cell transplantation: an international multicenter study. Blood. 2015;125:2164-72.

70. Harmatz P, Cattaneo F, Ardigò D, Geraci S, Hennermann JB, Guffon N, et al. Enzyme replacement therapy with velmanase alfa (human recombinant alpha-mannosidase): Novel global treatment response model and outcomes in patients with alpha-mannosidosis. Mol Genet Metab. 2018:124:152-60

71. Ceccarini M, Codini M, Conte C, Patria F, Cataldi S, Bertelli M, et al. Alphamannosidosis: therapeutic strategies. Int J Mol Sci. 2018;19:1500.

72. Häberle J, Burlina A, Chakrapani A, Dixon M, Karall D, Lindner M, et al. Suggested guidelines for the diagnosis and management of urea cycle disorders: first revision. J Inherit Metab Dis. 2019:42:1192-230.
73. Stockler-Ipsiroglu S, Apatean D, Battini R, DeBrosse S, Dessoffy K, Edvardson S, et al. Arginine:glycine amidinotransferase (AGAT) deficiency: clinical features and long term outcomes in 16 patients diagnosed worldwide. Mol Genet Metab. 2015;116:252-9.

74. Wassenberg T, Molero-Luis M, Jeltsch K, Hoffmann GF, Assmann B, Blau N, et al. Consensus guideline for the diagnosis and treatment of aromatic l-amino acid decarboxylase (AADC) deficiency. Orphanet J Rare Dis. 2017;12:12.

75. Kojima K, Nakajima T, Taga N, Miyauchi A, Kato M, Matsumoto A, et al. Gene therapy improves motor and mental function of aromatic l-amino acid decarboxylase deficiency. Brain. 2019;142:322-33.

76. Groeschel S, Kühl J-S, Bley AE, Kehrer C, Weschke B, Döring M, et al. Long-term outcome of allogeneic hematopoietic stem cell transplantation in patients with juvenile metachromatic leukodystrophy compared with nontransplanted control patients. JAMA Neurol. 2016;73:1133.

77. Sessa M, Lorioli L, Fumagalli F, Acquati S, Redaelli D, Baldoli C, et al. Lentiviral haemopoietic stem-cell gene therapy in early-onset metachromatic leukodystrophy: an ad-hoc analysis of a non-randomised, openlabel, phase 1/2 trial. Lancet. 2016;388:476-87.

78. Malm G, Mansson J-E, Winiarski J, Mosskin M, Ringden O. Five-year follow-up of two siblings with aspartylglucosaminuria undergoing allogeneic stem-cell transplantation from unrelated donors. Transplantation. 2004;78:415-9.

79. Rafiq M, Flanagan SE, Patch A-M, Shields BM, Ellard S, Hattersley AT. Effective treatment with oral sulfonylureas in patients with diabetes due to sulfonylurea receptor 1 (SUR1) mutations. Diabetes Care. 2008:31:204-9.

80. Vaxillaire M, Dechaume A, Busiah K, Cave H, Pereira S, Scharfmann R, et al. New ABCC8 mutations in relapsing neonatal diabetes and clinical features. Diabetes. 2007;56:1737-41.

81. Parini R, Deodato F. Intravenous enzyme replacement therapy in mucopolysaccharidoses: clinical effectiveness and limitations. Int J Mol Sci. 2020:21:2975

82. Jay AM, Conway RL, Feldman GL, Nahhas F, Spencer L, Wolf B. Outcomes of individuals with profound and partial biotinidase deficiency ascertained by newborn screening in Michigan over 25 years. Genet Med. 2015;17:205-9.

83. Frazier DM, Allgeier C, Homer C, Marriage BJ, Ogata B, Rohr F, et al. Nutrition management guideline for maple syrup urine disease: An evidence- and consensus-based approach. Mol Genet Metab. 2014;112:210-7.

84. Molema F, Martinelli D, Hörster F, Kölker S, Tangeraas T, Koning B, et al. Liver and/or kidney transplantation in amino and organic acid-related inborn errors of metabolism: An overview on European data. J Inherit Metab Dis. 2020.

85. García-Cazorla A, Oyarzabal A, Fort J, Robles C, Castejón E, Ruiz-Sala P, et al. Two novel mutations in the BCKDK (Branched-Chain Keto-Acid Dehydrogenase Kinase) gene are responsible for a neurobehavioral deficit in two pediatric unrelated patients. Hum Mutat. 2014;35:470-7.

86. van Karnebeek CD, Sly WS, Ross CJ, Salvarinova R, Yaplito-Lee J, Santra $\mathrm{S}$, et al. Mitochondrial carbonic anhydrase VA deficiency resulting from CA5A alterations presents with hyperammonemia in early childhood. Am J Hum Genet. 2014:94:453-61.

87. Okano Y, Ohura T, Sakamoto O, Inui A. Current treatment for citrin deficiency during NICCD and adaptation/compensation stages: Strategy to prevent CTLN2. Mol Genet Metab. 2019;127:175-83.

88. Malicdan MCV, Vilboux T, Ben-Zeev B, Guo J, Eliyahu A, Pode-Shakked $B$, et al. A novel inborn error of the coenzyme Q10 biosynthesis pathway: cerebellar ataxia and static encephalomyopathy due to $\mathrm{COQ} 5$ C-methyltransferase deficiency. Hum Mutat. 2018;39:69-79.

89. Traschütz A, Schirinzi T, Laugwitz L, Murray NH, Bingman CA, Reich S, et al. Clinico-genetic, imaging and molecular delineation of COQ8AAtaxia: a multicenter study of 59 patients. Ann Neurol. 2020;88:251-63.

90. Vairo FP, Chwal BC, Perini S, Ferreira MAP, de Freitas Lopes AC, Saute JAM. A systematic review and evidence-based guideline for diagnosis and treatment of Menkes disease. Mol Genet Metab. 2019;126:6-13.

91. Brewer GJ, Askari F, Lorincz MT, Carlson M, Schilsky M, Kluin KJ, et al. Treatment of Wilson disease with ammonium tetrathiomolybdate. Arch Neurol. 2006;63:521.

92. Schilsky ML. Wilson disease. Clin Liver Dis. 2017;21:755-67. 
93. Dunbar M, Jaggumantri S, Sargent M, Stockler-Ipsiroglu S, van Karnebeek CDM. Treatment of X-linked creatine transporter (SLC6A8) deficiency: systematic review of the literature and three new cases. Mol Genet Metab. 2014;112:259-74.

94. Schwahn BC, Van Spronsen FJ, Belaidi AA, Bowhay S, Christodoulou J, Derks TG, et al. Efficacy and safety of cyclic pyranopterin monophosphate substitution in severe molybdenum cofactor deficiency type A: a prospective cohort study. Lancet. 2015;386:1955-63.

95. Morris AAM, Kožich V, Santra S, Andria G, Ben-Omran TIM, Chakrapani $A B$, et al. Guidelines for the diagnosis and management of cystathionine beta-synthase deficiency. J Inherit Metab Dis. 2017;40:49-74.

96. Banka S, Blom HJ, Walter J, Aziz M, Urquhart J, Clouthier CM, et al. Identification and characterization of an inborn error of metabolism caused by dihydrofolate reductase deficiency. Am J Hum Genet. 2011;88:216-25

97. Anikster Y, Haack TB, Vilboux T, Pode-Shakked B, Thöny B, Shen N, et al. Biallelic mutations in DNAJC12 cause hyperphenylalaninemia, dystonia, and intellectual disability. Am J Hum Genet. 2017:100:257-66.

98. van Rijt WJ, Jager EA, Allersma DP, Aktuğlu Zeybek AÇ, Bhattacharya K, Debray F-G, et al. Efficacy and safety of D, L-3-hydroxybutyrate (D, $\mathrm{L}-3-\mathrm{HB}$ ) treatment in multiple acyl-CoA dehydrogenase deficiency. Genet Med. 2020;22:908-16.

99. Ziats MN, Comeaux MS, Yang Y, Scaglia F, Elsea SH, Sun Q, et al. Improvement of regressive autism symptoms in a child with TMLHE deficiency following carnitine supplementation. Am J Med Genet Part A. $2015 ; 167: 2162-7$

100. Al-Baradie RS, Chaudhary MW. Diagnosis and management of cerebral folate deficiency A form of folinic acid-responsive seizures. Neurosciences. 2014;19:312-6.

101. Alter AS, Engelstad K, Hinton VJ, Montes J, Pearson TS, Akman Cl, et al. Long-term clinical course of Glut1 deficiency syndrome. J Child Neurol. 2015;30:160-9.

102. Hainque E, Gras D, Meneret A, Atencio M, Luton M-P, Barbier M, et al. Long-term follow-up in an open-label trial of triheptanoin in GLUT1 deficiency syndrome: a sustained dramatic effect. J Neurol Neurosurg Psychiatry. 2019;90:1291-3.

103. Häberle J, Shahbeck N, Ibrahim K, Schmitt B, Scheer I, O'Gorman R, et al. Glutamine supplementation in a child with inherited GS deficiency improves the clinical status and partially corrects the peripheral and central amino acid imbalance. Orphanet J Rare Dis. 2012;7:48.

104. Bjoraker KJ, Swanson MA, Coughlin CR, Christodoulou J, Tan ES, Fergeson $\mathrm{M}$, et al. Neurodevelopmental outcome and treatment efficacy of benzoate and dextromethorphan in siblings with attenuated nonketotic hyperglycinemia. J Pediatr. 2016;170:234-9.

105. Khaikin Y, Sidky S, Abdenur J, Anastasi A, Ballhausen D, Buoni S, et al. Treatment outcome of twenty-two patients with guanidinoacetate methyltransferase deficiency: An international retrospective cohort study. Eur J Paediatr Neurol. 2018;22:369-79.

106. Miyake Z, Nakamagoe K, Yoshida K, Kondo T, Tamaoka A. Deferasirox might be effective for microcytic anemia and neurological symptoms associated with aceruloplasminemia: a case report and review of the literature. Intern Med. 2020;59:1755-61.

107. Donti TR, Blackburn PR, Atwal PS. Holocarboxylase synthetase deficiency pre and post newborn screening. Mol Genet Metab Reports. 2016;7:40-4.

108. Kubaski F, Yabe H, Suzuki Y, Seto T, Hamazaki T, Mason RW, et al. Hematopoietic stem cell transplantation for patients with mucopolysaccharidosis II. Biol Blood Marrow Transplant. 2017:23:1795-803.

109. Papa FT, Mancardi MM, Frullanti E, Fallerini C, Della Chiara V, ZalbaJadraque $L$, et al. Personalized therapy in a GRIN1 mutated girl with intellectual disability and epilepsy. Clin Dysmorphol. 2018;27:18-20.

110. Pierson TM, Yuan H, Marsh ED, Fuentes-Fajardo K, Adams DR, Markello T, et al. GRIN2A mutation and early-onset epileptic encephalopathy: personalized therapy with memantine. Ann Clin Transl Neurol. 2014;1:190-8

111. Hausman-Kedem M, Menascu S, Greenstein Y, Fattal-Valevski A. Immunotherapy for GRIN2A and GRIN2D-related epileptic encephalopathy. Epilepsy Res. 2020;163:106325.

112. Soto D, Olivella M, Grau C, Armstrong J, Alcon C, Gasull X, et al. I-Serine dietary supplementation is associated with clinical improvement of loss-of-function GRIN2B -related pediatric encephalopathy. Sci Signal. 2019;12:eaaw0936.

113. Li D, Yuan H, Ortiz-Gonzalez XR, Marsh ED, Tian L, McCormick EM, et al. GRIN2D recurrent de novo dominant mutation causes a severe epileptic encephalopathy treatable with NMDA receptor channel blockers. Am J Hum Genet. 2016;99:802-16.

114. Fuchs SA, Schene IF, Kok G, Jansen JM, Nikkels PGJ, van Gassen KLI, et al. Aminoacyl-tRNA synthetase deficiencies in search of common themes. Genet Med. 2019:21:319-30.

115. Kok G, Tseng L, Schene IF, Dijsselhof ME, Salomons G et al. Treatment of ARS-deficiencies with specific amino acids. Under Review.

116. Grünert SC, Wendel U, Lindner M, Leichsenring M, Schwab KO, Vockley J, et al. Clinical and neurocognitive outcome in symptomatic isovaleric acidemia. Orphanet J Rare Dis. 2012;7:9.

117. Incecik F, Bisgin A, YIlmaz M. MEDNIK syndrome with a frame shift causing mutation in AP1S1 gene and literature review of the clinical features. Metab Brain Dis. 2018;33:2065-8.

118. Lenz D, Stahl M, Seidl E, Schöndorf D, Brennenstuhl H, Gesenhues $F$, et al. Rescue of respiratory failure in pulmonary alveolar proteinosis due to pathogenic MARS1 variants. Pediatr Pulmonol. 2020;55:3057-66.

119. Coelho D, Kim JC, Miousse IR, Fung S, du Moulin M, Buers I, et al. Mutations in ABCD4 cause a new inborn error of vitamin B12 metabolism. Nat Genet. 2012;44:1152-5.

120. Baumgartner MR, Hörster F, Dionisi-Vici C, Haliloglu G, Karall D, Chapman KA, et al. Proposed guidelines for the diagnosis and management of methylmalonic and propionic acidemia. Orphanet J Rare Dis. 2014;9:130

121. Lee T, Takami Y, Yamada K, Kobayashi H, Hasegawa Y, Sasai H, et al. A Japanese case of mitochondrial 3-hydroxy-3-methylglutaryl-CoA synthase deficiency who presented with severe metabolic acidosis and fatty liver without hypoglycemia. JIMD Rep. 2019;48:19-25.

122. Grünert SC, Sass JO. 2-methylacetoacetyl-coenzyme A thiolase (betaketothiolase) deficiency: one disease - two pathways. Orphanet J Rare Dis. 2020;15:106.

123. van Karnebeek CDM, Ramos RJ, Wen X-Y, Tarailo-Graovac M, Gleeson JG, Skrypnyk C, et al. Bi-allelic GOT2 mutations cause a treatable malate-aspartate shuttle-related encephalopathy. Am J Hum Genet. 2019;105:534-48

124. Dahlin M, Martin DA, Hedlund Z, Jonsson M, Döbeln U, Wedell A The ketogenic diet compensates for AGC1 deficiency and improves myelination. Epilepsia. 2015;56:e176-81.

125. El-Hattab AW, Adesina AM, Jones J, Scaglia F. MELAS syndrome: clinical manifestations, pathogenesis, and treatment options. Mol Genet Metab. 2015;116:4-12

126. Ohsawa Y, Hagiwara H, Nishimatsu SI, Hirakawa A, Kamimura N, Ohtsubo $\mathrm{H}$, et al. Taurine supplementation for prevention of stroke-like episodes in MELAS: a multicentre, open-label, 52-week phase III trial. J Neurol Neurosurg Psychiatry. 2019:90:529-36.

127. Tam A, AIDhaheri NS, Mysore K, Tessier ME, Goss J, Fernandez LA, et al. Improved clinical outcome following liver transplant in patients with ethylmalonic encephalopathy. Am J Med Genet A. 2019:179:1015-9.

128. Ortigoza-Escobar JD, Alfadhel M, Molero-Luis M, Darin N, Spiegel R, de Coo IF, et al. Thiamine deficiency in childhood with attention to genetic causes: Survival and outcome predictors. Ann Neurol. 2017;82:317-30.

129. Trinh J, Imhoff S, Dulovic-Mahlow M, Kandaswamy KK, Tadic V, Schäfer I, et al. Novel NAXE variants as a cause for neurometabolic disorder: implications for treatment. J Neurol. 2020;267:770-82.

130. Patterson MC, Vecchio D, Prady H, Abel L, Wraith JE. Miglustat for treatment of Niemann-Pick $C$ disease: a randomised controlled study. Lancet Neurol. 2007:6:765-72.

131. Ory DS, Ottinger EA, Farhat NY, King KA, Jiang $X$, Weissfeld $L$, et al. Intrathecal 2-hydroxypropyl- $\beta$-cyclodextrin decreases neurological disease progression in Niemann-Pick disease, type C1: a non-randomised, open-label, phase 1-2 trial. Lancet. 2017;390:1758-68.

132. Huppke P, Weissbach S, Church JA, Schnur R, Krusen M, Dreha-Kulaczewski S, et al. Activating de novo mutations in NFE2L2 encoding NRF2 cause a multisystem disorder. Nat Commun. 2017;8:818. 
133. de Brouwer APM, van Bokhoven H, Nabuurs SB, Arts WF, Christodoulou J, Duley J. PRPS1 mutations: four distinct syndromes and potential treatment. Am J Hum Genet. 2010;86:506-18.

134. Brasil S, Pascoal C, Francisco R, Marques-da-Silva D, Andreotti G, Videira P, et al. CDG therapies: from bench to bedside. Int J Mol Sci. 2018;19:1304

135. Martínez-Monseny AF, Bolasell M, Callejón-Póo L, Cuadras D, Freniche V, Itzep DC, et al. AZATAX: acetazolamide safety and efficacy in cerebellar syndrome in PMM2 congenital disorder of glycosylation (PMM2-CDG). Ann Neurol. 2019;85:740-51.

136. Lubout CMA, Goorden SMI, van den Hurk K, Jaeger B, Jager NGL, van Koningsbruggen $S$, et al. Successful treatment of hereditary folate malabsorption with intramuscular folinic acid. Pediatr Neurol. 2020;102:62-6.

137. Hatch J, Coman D, Clayton P, Mills P, Calvert S, Webster RI, et al. Norma neurodevelopmental outcomes in PNPO deficiency: a case series and literature Review. JIMD Rep. 2015;91-7.

138. Sofou K, Dahlin M, HallböökT, Lindefeldt M, Viggedal G, Darin N Ketogenic diet in pyruvate dehydrogenase complex deficiency: shortand long-term outcomes. J Inherit Metab Dis. 2017:40:237-45.

139. Jauhari P, Sankhyan N, Vyas S, Singhi P. Thiamine responsive pyruvate dehydrogenase complex deficiency: a potentially treatable cause of Leigh's disease. J Pediatr Neurosci. 2017;12:265.

140. Bedoyan JK, Hecht L, Zhang S, Tarrant S, Bergin A, Demirbas D, et al. A novel null mutation in the pyruvate dehydrogenase phosphatase catalytic subunit gene (PDP1) causing pyruvate dehydrogenase complex deficiency. JIMD Rep. 2019;48:26-35.

141. Barić I, Staufner C, Augoustides-Savvopoulou P, Chien Y-H, Dobbelaere D, Grünert SC, et al. Consensus recommendations for the diagnosis, treatment and follow-up of inherited methylation disorders. J Inherit Metab Dis. 2017:40:5-20.

142. Witters P, Tahata S, Barone R, Ounap K, Salvarinova R, Grønborg S, et al. Clinical and biochemical improvement with galactose supplementation in SLC35A2-CDG. Genet Med. 2020;22:1102-7.

143. Byrne AB, Arts P, Polyak SW, Feng J, Schreiber AW, Kassahn KS, et al. Identification and targeted management of a neurodegenerative disorder caused by biallelic mutations in SLC5A6. NPJ Genomic Med. 2019;4:28.

144. Verrips A, Dotti MT, Mignarri A, Stelten BML, Verma S, Federico A. The safety and effectiveness of chenodeoxycholic acid treatment in patients with cerebrotendinous xanthomatosis: two retrospective cohort studies. Neurol Sci. 2020;41:943-9.
145. Vogel KR, Ainslie GR, Walters DC, McConnell A, Dhamne SC, Rotenberg $A$, et al. Succinic semialdehyde dehydrogenase deficiency, a disorder of GABA metabolism: an update on pharmacological and enzyme-replacement therapeutic strategies. J Inherit Metab Dis. 2018;41:699-708.

146. Zhu B, Wu J, Chen G, Chen L, Yao Y. Whole exome sequencing identifies a novel mutation of TPK1 in a Chinese Family with Recurrent Ataxia. J Mol Neurosci. 2020;70:1237-43.

147. Tabarki B, Alfadhel M, AlShahwan S, Hundallah K, AlShafi S, AlHashem A. Treatment of biotin-responsive basal ganglia disease: Open comparative study between the combination of biotin plus thiamine versus thiamine alone. Eur J Paediatr Neurol. 2015;19:547-52.

148. Trakadis YJ, Alfares A, Bodamer OA, Buyukavci M, Christodoulou J, Connor $\mathrm{P}$, et al. Update on transcobalamin deficiency: clinical presentation, treatment and outcome. J Inherit Metab Dis. 2014;37:461-73.

149. Schulz A, Ajayi T, Specchio N, de Los RE, Gissen P, Ballon D, et al. Study of intraventricular cerliponase Alfa for CLN2 disease. N Engl J Med. 2018;378:1898-907.

150. Peña-Quintana L, Scherer G, Curbelo-Estévez ML, Jiménez-Acosta F, Hartmann B, La Roche F, et al. Tyrosinemia type II: mutation update, 11 novel mutations and description of 5 independent subjects with a novel founder mutation. Clin Genet. 2017;92:306-17.

151. Willemsen MA, Verbeek MM, Kamsteeg E-J, de Rijk-van Andel JF, Aeby A, Blau N, et al. Tyrosine hydroxylase deficiency: a treatable disorder of brain catecholamine biosynthesis. Brain. 2010;133:1810-22.

152. Rilstone JJ, Alkhater RA, Minassian BA. Brain dopamine-serotonin vesicular transport disease and its treatment. N Engl J Med. 2013;368:543-50.

153. Eichler F, Duncan C, Musolino PL, Orchard PJ, De Oliveira S, Thrasher AJ, et al. Hematopoietic stem-cell gene therapy for cerebral adrenoleukodystrophy. N Engl J Med. 2017;377:1630-8.

154. Engelen M, Kemp S, de Visser M, van Geel BM, Wanders RJA, Aubourg P, et al. X-linked adrenoleukodystrophy (X-ALD): clinical presentation and guidelines for diagnosis, follow-up and management. Orphanet J Rare Dis. 2012;7:51.

\section{Publisher's Note}

Springer Nature remains neutral with regard to jurisdictional claims in published maps and institutional affiliations.
Ready to submit your research? Choose BMC and benefit from:

- fast, convenient online submission

- thorough peer review by experienced researchers in your field

- rapid publication on acceptance

- support for research data, including large and complex data types

- gold Open Access which fosters wider collaboration and increased citations

- maximum visibility for your research: over $100 \mathrm{M}$ website views per year

At BMC, research is always in progress.

Learn more biomedcentral.com/submissions 